\title{
1 Silver thiosulfate and Benzyladenine in combination with pruning \\ 2 additively feminizes cassava flowers and modulates transcriptome
}

3 Oluwasanya Deborah ${ }^{1,2}$, Esan Olayemisi ${ }^{2}$, Hyde Peter $^{1}$, Kulakow Peter ${ }^{2}$, Setter Tim $^{1 *}$

$4{ }^{1}$ Section of Soil and Crop Sciences, School of Integrative Plant Science, Cornell University, Ithaca,

$5 \quad \mathrm{NY}, \mathrm{USA}$

$6{ }^{2}$ Cassava Breeding Unit, International Institute of Tropical Agriculture, Ibadan, Oyo State, Nigeria

7 * Correspondence:

8 Tim Setter

9 tls1@cornell.edu

10 Keywords: Cassava flowers, Sex determination, Ethylene, Silver thiosulfate, Cytokinin,

11 Benzyladenine, PGR, Pruning.

\section{Abstract}

13 Cassava, a tropical storage-root crop, is a major source of food security for millions in the tropics.

14 Cassava breeding however is hindered by the poor development of flowers and female flowers in

15 particular, since flower development is strongly skewed towards male flowers. Our objectives were

16 to test plant growth regulator and pruning treatments for their effectiveness in field conditions in

17 improving flower production and fruit set in cassava. Pruning the fork type branches that arise at the

18 shoot apex immediately below newly formed inflorescences stimulated inflorescence and floral

19 development. The anti-ethylene silver thiosulfate (STS) also increased flower abundance. Both

20 pruning and STS increased flower numbers without influencing sex ratios. In contrast, the cytokinin

21 benzyladenine (BA) feminized flowers without increasing flower abundance. Combining pruning and

22 STS treatments led to an additive increase in flower abundance; with the addition of BA, over $80 \%$ of

23 flowers were females. This three-way treatment combination of pruning+STS+BA also led to an

24 increase in fruit development. Transcriptomic analysis of gene expression in tissues of the apical

25 region and developing inflorescence revealed that the enhancement of female flower development by

26 STS+BA was accompanied by the downregulation in of several genes associated with repression of

27 flowering, including Tempranillo 1 (TEM1), GA receptor GID1b, and ABA signaling genes ABI1 
and PP2CA. We conclude that treatments with pruning, STS and BA create widespread changes on the network of hormone signaling and regulatory factors beyond ethylene and cytokinin.

\section{Introduction}

31 Cassava (Manihot esculenta) is a perennial tropical plant of the Euphorbiaceae family cultivated as an annual crop for its starchy storage roots (Liu et al. 2014). It constitutes an important source of calories for over 750 million people (Tuteja et al. 2012). It is also a source of starch with expanding potential for industrial applications (Li et al. 2017). Continual crop improvement is required to ensure efficient cassava production to meet growing needs from an increasing population matched with changing environments globally. Cassava improvement has recently received renewed attention with major projects to investigate the potential use of genomic selection in breeding (Wolfe et al. 2017), detailed studies into its source-sink relationships (Sonnewald et al. 2020) and investigations to improve its photosynthetic efficiency (De Souza and Long 2018). These improvement efforts are geared towards small holder farmers with interest in translating cassava end product quality traits into breeding outcomes (Iragaba 2019). Although cassava can be clonally propagated by stem cuttings, achieving crop improvement requires genetic hybridization and associated recombination, and hence the need for a means of sexual propagation that is timely and synchronous amongst a diverse genetic population.

In the Euphorbiaceae family, sexual reproductive structures are referred to as cyathia, which is a modification that has provided this family the advantage of shifting from wind pollination to insect pollination (Horn et al. 2012) . A single cassava male cyathium is comprised of multiple reduced stamens (Perera et al. 2013) while a female cyathium possesses a trilocular ovary, meaning that upon pollination, fruits are capable of producing three seeds (Nassar 1980). Female and male cyathia are borne on the same inflorescence separately. For ease of description, cyathia in this study will be referred to as flowers. Inflorescences and associated flowers are developed from the shoot apical meristem. Following floral initiation, the two to three buds beneath the inflorescence develop into branches forming a fork. Fork type branches each bear new shoot apical meristems in sympodial growth which after some growth form branches and inflorescences, in turn, at tier 2, tier 3, etc. 
58 There are five bottlenecks with cassava's reproductive development that challenge breeding. These are (1) late flowering (or in some cases no flowering at all) of certain genotypes with traits of interest, (2) premature abortion of flowers before anthesis, (3) disproportionate number of male flowers and in some cases no female flowers, in cases where flowers are not aborted, (4) non synchronous development of flowers, (5) low probability of fruit development even when flowering and pollination are successful (Adeyemo et al. 2017; Hyde et al. 2020; Ceballos et al. 2004; Ceballos et al. 2016; Halsey et al. 2008; Souza et al. 2020).

Investigations into the reproductive biology of cassava has led to the development of several potential interventions to improve reproductive performance in cassava: transgenic intervention by overexpressing Flowering Locus FT (Adeyemo et al. 2017; Odipio et al. 2020; Bull et al. 2017), modulating photoperiod and temperature to accelerate flowering time (Adeyemo et al. 2019), application of silver thiosulfate to enhance flower development and longevity (STS) (Hyde et al. 2020), or pruning young subtending branches to alleviate flower abortion (Pineda et al. 2020). None so far has focused on increasing the proportion of female flowers. Female flowers are critical to cassava breeding; however, flowers on cassava inflorescences are typically about $90 \%$ male, and each female flower produces only three seeds, at most. In other members of the Euphorbiaceae family, synthetic cytokinin, Benzyladenine, has been used to increase female flower numbers and fruits (Fröschle et al. 2017; Fu et al. 2014; Pan and Xu 2011).

To increase the proportion of female flowers in cassava we tested the effect of STS, BA and pruning, singly and combined, on the first flowering event (i.e., flowering at tier 1) under field conditions in Nigeria. We also analyzed the transcriptome of young apical tissues in control plants and in plants receiving either pruning or STS + BA, or the combined set of treatments. We specifically studied the expression pattern of differentially expressed genes relevant to hormone signaling and flower development. Our findings indicate that STS or pruning increase flower numbers over the control but have no effect on the female to male ratios. While BA is able to completely feminize flowers, it does not affect the number of total flowers. Combining BA with either STS or pruning or both allows for

86 development of predominantly female flowers on a larger population of flowers. The transcriptome 
87 changes under STS+BA treatment indicates effects on other hormone signaling beyond ethylene and 88 cytokinin.

\section{$892 \quad$ Materials and methods}

\subsection{Plant materials}

91 Three genotypes, representing three flowering times and extents of flower prolificacy were used for 92 plant growth regulator (PGR) studies. These were IITA-TMS-IBA980002 (early and profuse), IITA93 TMS-IBA30572 (middle genotype) and TMEB419 (late and poor flowering). In this paper these 94 genotypes will be referred to as 0002, 30572, and 419, respectively. 0002 was used to optimize the 95 method of plant growth regulator (PGR) application in 2017. This experiment was conducted 96 between June and December of 2017. Experiments examining the effect of PGRs on female flower 97 development were conducted between June and December of 2018 and 2019.

\subsection{Field conditions}

99 All experiments for phenotyping were conducted under field conditions at the International Institute 100 of Tropical Agriculture (IITA), Oyo State, Ibadan $\left(7.4^{\circ} \mathrm{N}\right.$ and $3.9^{\circ} \mathrm{E}, 230 \mathrm{~m}$ asl). The soil was an 101 Alfisol (oxicpaleustalf) (Moormann et al. 1975). The land was tilled and ridged with $1 \mathrm{~m}$ spacing;

102 plants were sown on top of the ridge. The land in 2017 in Experiment I was previously planted with 103 yam while the field in 2018 and 2019 in Experiment II was previously planted with maize; no extra 104 nutrients or soil amendments were added to the soil. Fields were kept free of weeds with hand 105 weeding.

\subsection{Plant growth regulators and method of application}

107 Silver thiosulfate (STS) was prepared by mixing 1 part $0.1 \mathrm{M}$ silver nitrate $\left(\mathrm{AgNO}_{3}\right)$ dropwise with 4 108 parts $0.1 \mathrm{M}$ sodium thiosulfate $\left(\mathrm{Na}_{2} \mathrm{~S}_{2} \mathrm{O}_{3}\right)$, yielding a $20 \mathrm{mM}$ stock solution. The stock solution was 109 diluted with distilled water to the required concentration as specified in each experiment.

110 Benzyladenine (BA) solution was prepared by diluting a 1.9\% (w/v) BA stock (MaxCel@, Valent

111 BioSciences Corporation, Libertyville, IL, USA) with distilled water to respective concentrations.

112 PGRs were applied either by spray (about $5 \mathrm{~mL}$ ) to the shoot apex, every seven days or by the

113 "petiole feeding" method every 14 days. In the petiole feeding method, the leaf blade was removed 114 using a surgical scissors and the petiole was inserted into a 15-mL conical-bottom centrifuge tube 115 (Falcon Brand, Corning, NY, USA) containing 5-10 mL of PGR solution. PGR was taken up via 
116 the petiole into xylem from which it was distributed internally to target organs in the leaves and apex

117 (Figure 1a). Petioles were allowed to remain immersed in the PGR solution for 72h after which tubes

118 were removed. On weeks with petiole feeding, spray treatments were applied $24 \mathrm{~h}$ after petiole

119 treatments. PGR treatments were initiated six weeks after planting.

\section{$121 \quad 2.4 \quad$ Pruning reproductive branches}

122 Shoot apexes were inspected weekly using headband magnifier glasses (10X magnification) to

123 identify and score forking events. In plants that had forked, young reproductive branches, $2 \mathrm{~cm}$ or

124 smaller, were excised carefully without damage to inflorescence using surgical blades, as previously

125 described by Pineda et al. (2020). Lateral branches which developed about $10 \mathrm{~cm}$ below the shoot

126 apex were excised periodically until fruit development. Photos of pruned and unpruned plants are

127 shown in (Figure 1 b,c)

\subsection{Flower data collection}

130 The number of male and female flowers and fruits were counted for each plant weekly and recorded

131 using Field Book computer application (Rife and Poland 2014). Data was collected for at least 20

132 weeks. For analysis, the maximum flower or fruit count for each plant over the 20-week period was

133 used to represent response to treatment.

\section{$135 \quad 2.6 \quad$ PGR Experiment I: Application method optimization}

136 A matrix of 100 plants of IITA-TMS-IBA980002 were grown in a 10 x 10 arrangement at a planting

137 distance of $1 \mathrm{~m} \times 1 \mathrm{~m}$. The matrix was divided into 10 plots to allow for treatment assignments. At six

138 weeks after planting, 10 PGR treatments were randomly assigned to each plot, with each plant as the

139 experimental unit. Treatments were various combinations of petiole-fed STS or $\mathrm{H}_{2} \mathrm{O}$ with spray-

140 applied BA at four flower developmental stages. To determine the effect due to STS alone, STS or

$141 \mathrm{H}_{2} \mathrm{O}$ were applied by petiole feeding in combination with $\mathrm{H}_{2} \mathrm{O}$ sprayed to the shoot apex. Five mL of

$1428 \mathrm{mM}$ STS was used for the first treatment then reduced to $5 \mathrm{~mL}$ of $4 \mathrm{mM}$ STS for subsequent 
143 treatments to limit phytotoxicity. Concentration of BA used was $0.22 \mathrm{mM}$. Treatments are

144 summarized in Table 1.

\section{$145 \quad$ 2.7 PGR Experiment II: PGR and pruning effect on female flower development}

146 In 2018 and 2019, experiments were conducted using a split-split-split plot design. Each experiment 147 comprised six plots, each of which were split into three subplots each with one of the genotypes.

148 Each genotype subplot was split into 5 PGR treatments (as shown in Table 2) and finally each

149 treatment was split into two pruning levels - pruned versus unpruned. In 2018, a total of 1440 plants 150 were sown, while in 2019, 720 plants were sown. Petiole feeding of STS and BA was with either 10 $151 \mathrm{~mL}$ of $2 \mathrm{mM}$ STS ( $5 \mathrm{~mL}$ of $4 \mathrm{mM}$ STS was used in the first month of treatment in 2018), $5 \mathrm{~mL}$ of 0.5 $152 \mathrm{mM} \mathrm{BA}$, or a mixture of $5 \mathrm{~mL}$ of $2 \mathrm{mM} \mathrm{STS}$ and $0.125 \mathrm{mM} \mathrm{BA}$. Spray treatments of BA were 153 applied to the shoot apex with $0.5 \mathrm{mM}$ BA.

\subsection{Statistical Analysis}

156 Count data, such as the numbers of total flowers, female flowers, and fruits were modelled using the

157 negative binomial model while ratios such as the proportion of total flowers that were female and 158 proportion of female flowers that set fruit were modelled using the binomial model. Due to

159 similarities of genotypic response to PGR and pruning (different magnitudes of changes but similar 160 trends), the means of genotypes used in 2018 and 2019 are reported here.

162 Models were built using the package called Generalized Linear Mixed Models using Template Model 163 Builder (glmmTMB) (Brooks et al. 2017) in R (Team 2013). Sources of variation for the experiment 164 were STS treatment (+STS, -STS) and BA timing, and the interaction between STS treatment and 165 BA timing. Plots were random effects. For Experiment II, sources of variation were PGR treatment, 166 pruning and the interaction between PGR treatment and pruning. Year was analyzed as a fixed effect 167 while plot as a random effect. The emmeans package (Lenth 2019) was used for post-hoc tests.

168 Multiple means comparison was carried out using the Tukey-HSD method. 
171 IITA-TMS-IBA980002 was grown in a greenhouse at the Guterman Bioclimatic laboratory (Cornell

172 University, Ithaca, NY, USA) as described by Hyde et al (2020) and exposed to one of four treatment

173 combinations (a $2 \times 2$ matrix of treatments): a) either control or pruned at first inflorescence

174 appearance, and b) either a control or PGRs with a combination of petiole-fed STS, and apex-sprayed

175 BA. These were applied to plants at tier 1 of fork branching. Young inflorescence tissue, about 0.25

$176-0.5 \mathrm{~cm}$, comprising the shoot apex and some bracts but excluding fork-type branches were

177 harvested from control, pruned and PGR treated plants. Samples were collected four days after

178 pruning or at a similar developmental stage in unpruned plants.

180 Total RNA was extracted from each sample by a modified CTAB protocol. Samples were ground to

181 a fine powder in a mortar and pestle chilled with liquid $\mathrm{N}_{2}$; about $0.15 \mathrm{~mL}$ of the powder was

182 vigorously mixed for $5 \mathrm{~min}$ with $0.4 \mathrm{~mL}$ of CTAB extraction buffer $(1 \%$ [w/v] CTAB detergent, 100 $183 \mathrm{mM}$ Tris-HCl [pH 8.0], 1.4 M NaCl, $20 \mathrm{mM}$ EDTA, and 2\% [v/v] 2-mercaptoethanol); $0.2 \mathrm{~mL}$ of

184 chloroform was added and mixed for $1 \mathrm{~min}$, tubes were centrifuged at 14,000 $\mathrm{g}$ for $10 \mathrm{~min}$ and 200

$185 \mu \mathrm{L}$ of the top layer was removed to a new tube. To these samples was added $700 \mu \mathrm{L}$ of Guanidine

186 buffer (4M guanidine thiocyanate, $10 \mathrm{mM}$ MOPS, pH 6.7) and $500 \mu \mathrm{L}$ of ethanol (100\%). This

187 mixture was applied to silica RNA columns (RNA mini spin column, Epoch Life Science, Missouri

188 City, TX, USA), then washed with $750 \mu \mathrm{L}$ of 1) MOPS-ethanol buffer (10 mM MOPS-HCl [pH 6.7],

$1891 \mathrm{mM}$ EDTA, containing 80\% [v/v] ethanol), 2) 80\% ethanol (twice), and 3) $10 \mu \mathrm{L}$ RNAase-free

190 water to elute the RNA (twice). The RNA quality was evaluated with a gel system (TapeStation

191 2200, Agilent Technologies, Santa Clara, CA, USA).

193 Differential Gene expression analysis was conducted using the DESeq2 package by Bioconductor

194 (Love et al. 2014). Each transcript was annotated by the best match between Manihot esculenta

195 genome v7 and the Arabidopsis genome as presented at Phytozome13 (Goodstein et al. 2012). Gene

196 ontology and enrichment analysis were carried out using the ShinyGO app

197 (http://bioinformatics.sdstate.edu/go/) (Ge et al. 2020).

198 A combined list of Arabidopsis flowering genes were obtained from the Max Planck Institute

199 (https://www.mpipz.mpg.de/14637/Arabidopsis_flowering_genes) and Flowering Interactive 
200 Database (FLOR-ID) (http://www.phytosystems.ulg.ac.be/florid/) (Bouché et al. 2016); a list of

201 hormone signaling genes sourced through the Database for Annotation, Visualization and Integrated

202 Discovery (DAVID) (https://david.ncifcrf.gov/) (Dennis et al. 2003) and a list of Cassava MADS-

203 Box MIKC genes were obtained from iTAK data-base (http://itak.feilab.net/cgi-

204 bin/itak/db_family_gene list.cgi?acc=MADS-MIKC\&plant=3983) (Zheng et al. 2016) were used to

205 determine expression pattern of genes by flowering, hormone signaling and MADS-Box categories.

\section{$3 \quad$ Results}

\subsection{PGR Experiment I: Application method optimization}

209 In previous studies under greenhouse growth conditions, STS spray treatments increased flower

210 numbers and longevity (Hyde et al. 2020); however, when sprayed onto leaves, cassava foliage

211 sometimes suffered phytotoxicity. It was possible to substantially decrease the quantity of STS used

212 with similar benefit if the spray was localized to the young folded leaves and region of the shoot

213 apical meristem. However, when these PGRs have been used in preliminary studies on cassava with

214 spray application in the field, their effectiveness has not been clear cut (Setter, personal

215 communication). A new petiole feeding method was developed, similar to that reported by Lin et al.

216 (2011). This method introduced more modest quantities of PGR internally via xylem of the petiole

217 and delivered these substances to the shoot such that phytotoxicity was decreased (Hyde and Setter

218 personal communication). In the current studies we used petiole feeding as a method of STS

219 application in field studies. Further, we investigated whether BA applied as a spray to the immature

220 tissues, affects flower development as a sole treatment or when combined with STS delivered

221 through the petiole.

223 Compared to the control without any PGR treatment, STS significantly $(\mathrm{P} \leq 0.05)$ increased total 224 number of flowers as a sole treatment, and in combination with BA (Figure 2a). STS treatment 225 increased both the number of female flowers (Figure 2b) and male flowers. BA treatments did not 226 affect the total number of flowers (Figure 2a); however, in comparison with the control not treated 227 with STS, when BA was applied as a sole treatment throughout flower development (BA_Always) or 228 at the early stage (BA_Early), it created a weakly significant $(\mathrm{P} \leq 0.10)$ increase in the number of 
female flowers (Figure 2b). These increases were associated with a unique effect of BA on increasing the proportion of total flowers that were female (Figure $2 \mathrm{~d}$ ). In this case the interaction between STS and BA treatments was significant. Early and continuous BA treatments (with or without STS) significantly increased the fraction for female flowers relative to the controls. Later BA treatments (Mid or Late) did not significantly affect the fraction of female flowers. STS alone had a slightly higher fraction of flowers that were female (Figure $2 d$ ), but it significantly $(\mathrm{P} \leq 0.05)$ increased fruit numbers (Figure 2c). In contrast, BA did not affect fruit numbers. For total flower, female flower and fruit numbers the interaction between STS and BA treatment at different developmental stages was not significant $(\mathrm{P}<0.05)$.

\section{8}

\subsection{PGR Experiment II: PGR and pruning effect on female flower development}

239 From Experiment I, above, we obtained evidence that STS treatment increases flower and fruit 240 numbers and that spraying BA to the shoot apex feminized flowers and increased the proportion of

241 flowers that were female. In Experiment II, we tested two additional factors. First is the potential 242 effect on flowering of pruning branch shoots that arise just below the terminal meristem where 243 inflorescences initiated (Pineda et al. 2020). Second is the potential benefit of including BA in petiole

244 feeding rather than only via external spray to leaves and/or apical regions. We therefore investigated 245 the interaction between continuous BA sprays with 1) petiole-fed BA, 2) petiole-fed STS and 3) a 246 mixture of STS and BA (see Materials and Methods). We also increased the BA concentration to $2470.5 \mathrm{mM}$ and studied PGR effects with or without pruning (see Materials and Methods). The effect on 248 individual genotypes are shown in supplementary figure 1, while averaged, are presented below.

In the absence of pruning and STS, total flower numbers in BA-only treatments - whether applied by spray (BA) or via the combination of apical spray and petiole methods (BA+BA) - were not significantly different from the control (Figure 3a). In contrast, STS inclusive treatments (i.e. STS+BA and STS+BA+BA) in the absence of pruning significantly increased female flower numbers relative to the control. In the presence of pruning, the total number of flowers increased significantly in all PGR treatments and in the no-PGR pruning treatment relative to their unpruned counterparts. Pruning and STS had an additive effect, as this combination had the largest number of 
Female flower number

260 The effect of treatments on female flower numbers was similar to effects on total flower numbers.

261 BA-only PGR treatments (BA, BA+BA) were not significantly different from the no-PGR treatments

262 without pruning and with pruning (Figure 3b). STS-inclusive treatments (STS+BA, STS+BA+BA)

263 without pruning had significantly more female flowers than BA-only treatments and the no-PGR

264 control without pruning but was equivalent to BA+BA and control with pruning. STS-inclusive

265 treatments with pruning had the highest number of female flowers. (Figure $3 b$ ).

266 Fruit numbers

267 As with other traits, fruit numbers in BA-only treatments were not significantly different from

268 control in the absence or presence of pruning (Figure 3c). STS-inclusive treatments, however,

269 increased fruit numbers relative to the control in both the unpruned and pruned plants such that the

270 combination of pruning and STS yielded largest number of fruits.

271 Female proportion of total flowers

272 In the controls, female flowers represented 35 to $40 \%$ of the flowers in both un-pruned and pruned

273 plants, with the remainder male flowers (Figure 3d). In contrast, all treatments that included BA were

274 significantly different from the controls and had over $80 \%$ females, with and without pruning, and

275 with and without STS. Only plants that had flowers were included in this analysis (plants with no

276 flowers were excluded).

\section{$277 \quad 3.3 \quad$ Transcriptomics}

278 To advance our understanding of PGR and pruning effects on flowering regulatory processes, we 279 analyzed gene expression in response to PGR and pruning treatments. For this work, we used 280 treatments which had the largest effect in the field: a) STS+BA without pruning, b) STS+BA with

281 pruning, c) pruning without PGR treatment, and d) control (no PGRs and no pruning). This study

282 was conducted on the model genotype 0002, in a controlled environment green house.

\section{$283 \quad$ 3.3.1 Green house phenotype validation}

284 To validate treatment responses that were observed in the field with those in a controlled

285 environment greenhouse, we evaluated flowering traits with select treatments in the greenhouse.

286 Similar to the field study, the controls initiated inflorescences, but did not produce any mature

287 flowers, while pruning or STS+BA as sole treatments produced a modest, number of flowers (Figure 
$4 \mathrm{a})$; in the pruning treatment all the flowers were male, but in STS+BA, about $80 \%$ were female (Figure 4 b,c). Combining STS+BA with pruning increased total and female flower numbers by about three-fold compared to the PGR- or pruning-only treatments. As with field studies, BAcontaining treatments increased the number of female flowers and the proportion of flowers that were female (Figure 4 b,c). These findings confirmed a consistent response to treatments under field and greenhouse conditions.

\subsubsection{Identification of differentially expressed genes and enrichment analysis}

Transcriptome analysis was conducted for tissues of the shoot apical region and proceeded in three

phases (i) examining transcriptome changes due to pruning alone (design $=\sim$ pruning), (ii) examining transcriptome changes due to PGR alone (design $=\sim$ pgr), (iii) examining transcriptome changes due to the combination of pruning and PGR (design $=\sim$ pruning + pgr). This analysis revealed that the majority of the changes in the transcriptome was due the influence of the PGR treatments. Principle component (PC) analysis indicated that expression was not clearly grouped according to pruned versus unpruned treatments but was clearly grouped according to PGR-treated versus PGR untreated samples (Figure 5a). This grouping was along the first PC axis, which accounted for $54 \%$ of the variance. It appeared from the PC analysis that pruning had an intermediate effect in the positive direction along the first principal component whereas PGR had a more substantial effect in the same direction along PC1 axis; the combination of PGR and pruning gave the largest effect in the positive direction of PC1 axis. Analysis of the full model including pruning and PGR revealed that 5440 genes were differentially expressed at a 5\% false discovery rate (FDR) correction; 2448 genes were up regulated while 2952 genes were down regulated. Functional analysis revealed that in the PGRtreated versus controls, PGR-upregulated genes were enriched in pathways involving cell proliferation, cell maintenance, and biosynthetic processes; while PGR-down regulated genes were enriched in pathways involved in plant hormone signal transduction, photosynthesis and degradation metabolism, among others (Figure $6 \mathrm{a}, \mathrm{b})$.

\subsubsection{Identification of co-expressing differentially expressed genes}

314 Using DESeq2 statistical analysis we identified genes differentially expressed under the full model

315 (design $=\sim$ pruning + pgr) (Figure 7a). Among the four categories of treatment $(+/-$ PGR $x+/-$

316 pruning), expression was generally grouped according to whether the category included PGR versus

317 did not include PGR. Many genes in the plants that received the pruning treatment but were not

318 treated with PGR were intermediate between the control and the PGR-treated plants. By inspection 
319 of the fold-expression heatmap we selected a cluster of genes with exceptionally high fold changes

320 compared to expression profiles of other genes. Genes in this cluster had high expression in the

321 control, very low expression in PGR-treated plants, and intermediate expression with pruning only.

322 Enrichment analysis indicated that this cluster, consisting of 61 genes, was enriched with genes

323 involved in abscisic acid metabolism and response, terpenoid metabolism, abiotic stress response and

324 response to chemicals (Figure 7 b,c). This cluster suggests that regulation associated with the

325 treatments that stimulate flowering was a decrease in stress-associated genes which were expressed at

326 moderate levels in the control apical region.

\subsubsection{Pruning}

329 Twenty-one genes were differentially expressed in response to pruning as the principal treatment

330 (Figure 8a). This set was enriched in genes involved in response to wounding, herbivory and

331 jasmonic acid signaling (Figure 8b). Also upregulated in pruning were genes involved in terpene,

332 lipid and hormone metabolic pathways. Pruning increased expression of these genes in the presence

333 or absence of PGR treatments. Given that the tissues for this analysis were harvested $4 \mathrm{~d}$ after

334 pruning, it is not surprising that metabolic and signaling factors involved in wounding response were

335 expressed abundantly

\section{$336 \quad$ 3.3.2.3 Hormone signaling genes}

337 We examined the expression profile of 115 hormone signal-transduction genes that were

338 differentially expressed $\left(\mathrm{P}_{\mathrm{adj}}<0.05\right)$ in our samples (Figure 9; expression data for the full set of

339 select hormones signaling genes is available in Supplementary Figure 4). While many genes differed

340 only modestly between treatments, there was a cluster of genes with relatively high expression in the

341 control and substantially lower expression in the PGR treatments. This cluster included a GA

342 signaling gene (GID1b), and two repressors of ABA signaling (ABI1 and PP2CA) (Figure 9b). We

343 also found an auxin response gene (IAA16), and a JA response gene (TIFY10B) that were expressed

344 at a low level in the control, but they had slightly higher expression in PGR treatments, and the

345 highest expression in the pruned without PGR treatment (Figure 9c). Thus, the expression data

346 indicated that PGR treatments comprising anti-ethylene treatment STS and cytokinin treatment BA

347 influenced expression of genes in hormone signaling pathways other than cytokinin and ethylene 
348 pathways as shown above, suggesting these hormones have considerable breadth of impact in the

349 network of hormone signaling.

\subsubsection{Flowering genes}

351 Among genes known to be involved in various aspects of flowering, we identified 217 genes that 352 were differentially expressed $\left(\mathrm{P}_{\mathrm{adj}} \leq 0.05\right)$ in response to our experimental treatments (Figure 10a).

353 From the two clusters with the largest fold changes, two members of the GA flowering pathway

354 (GID1b, GA2ox2) and the TEM1 gene, a known flowering repressor, had the highest fold change 355 with relatively high expression in controls, and low expression in the PGR treatments (Figure 10 b,c).

356 Expression profiles of flowering genes organized by known flowering pathways are presented in

357 Supplementary Figure 3. Other flowering genes with large fold changes with respect to treatments 358 were HDA6, BRC1, FLD, NF-YA1, PNY, LUX and BRM (Figure 10 b,c).

\subsubsection{ABCDE MADS-Box TF}

360 Thirty of the 47 putative MADS-Box MIKC transcription factors (TFs) in cassava

361 (http://itak.feilab.net/cgi-bin/itak/db_family_gene list.cgi?acc=MADS-MIKC\&plant=3983) were

362 differentially expressed $(\mathrm{P} \leq 0.05)$ in response to PGR treatment or pruning (Supplementary Figure 2).

363 The fold changes in expression levels of MADS-Box TFs were notably smaller than for the gene

364 groups identified above. We, however, focused our attention on the flower organ development genes, 365 with respect to the ABCDE transcription factors (Supplementary Figure 5). Generally, the A, B, C 366 and E class genes had lower expression levels under PGR treatments while the D class genes had

367 higher expression under PGR treatments. In contrast, an AP3 gene - Manes.02G100400 (B class) and 368 SEP3 - Manes.13G009600 (E class) responded to pruning with increased expression with or without 369 PGR treatment. Among these MADS-Box factors, many responded in a PGR-specific manner in 370 which pruning without PGR was about the same as the control, but a few had lower expression in 371 response to pruning while maintaining expression with PGR treatments (B-class AP3

372 Manes.02G100400, E-class SEP3 Manes.13G009600).

\section{Discussion}

1) STS increased total flower and fruit numbers but did not affect female to male ratio.

375 A previous study demonstrated that STS, an anti-ethylene PGR, promotes flower development in 376 cassava (Hyde et al. 2020),. These authors showed that STS increased the duration of cassava flower 
production and retention (i.e., lifespan) by five-fold relative to the control, leading to a larger number

of total flowers. The present study is in line with this as STS alone increased the total number of

flowers by two-fold relative to the no STS controls; STS treatment increased production of both

female and male flowers, but it did not significantly alter the female to male ratios compared to the

no STS control. In addition to effects on flowering, the current study also showed that STS increases

fruit numbers (Figure 2, Figure 3).

383 In other plant systems, ethylene is widely recognized as playing a role in fruit development,

384 especially fruit ripening (Pech et al. 2018). Ethylene hastens flower senescence, and anti-ethylene treatments including STS have been developed to increase flower longevity (Serek et al. 2006). Ethylene has also been shown to affect early stages of fruit development and fruit set. In Pea and Arabidopsis, failure to develop fruit in the absence of pollination has been associated with ovary senescence arising from increased ethylene biosynthesis in ovaries (Orzáez and Granell 1997; Carbonell-Bejerano et al. 2011). In Zucchini squash, blocking ethylene perception by STS extended in response to gibberellins (Martínez et al. 2013).

In contrast to the masculinizing effect of STS on female flowers of Cannabis (Ram and Sett 1982) and Cucurbita (Den Nijs and Visser 1980), STS alone did not increase the tendency towards masculinity (Figure 2d). This could be because Cassava naturally produces a high fraction of male flowers when flowering is successful.

\section{2) Pruning and STS had similar effects}

397 Pruning of branches just below a newly initiated inflorescence has recently been shown to improve

398 flower development in cassava and increase the total number of flowers, fruits, and seeds (Pineda et al. 2020). Hence, pruning can have similar effects to those reported for STS (Hyde et al. 2020). In addition, we observed that while both pruning and STS increased the number of total flowers, and increased female flowers as a consequence of overall increase in flower numbers, these two treatments did not affect the ratio of female to male flowers (Figure 3 and 4). The similarity in mechanisms by which STS and pruning treatments elicit their effects is open for further investigation. 
In other members of Euphorbiaceae, cytokinin increased the female to male ratio as illustrated in Jatropha curcas (Chen et al. 2014; Pan et al. 2014; Pan and Xu 2011) and Plukenetia volubilis (Fu et al. 2014). More female flowers were developed under higher BA concentrations (Chen et al. 2014). This was also true for cassava in our studies with BA as a sole treatment. By increasing the concentration of BA between experiments I and II, we were able to increase the percentage of female flowers from about $12 \%$ in the untreated control, to a about $30 \%$ with $0.22 \mathrm{mM}$ BA to over $80 \%$ with $0.5 \mathrm{mM}$ BA (Figure 2 and

3). Other studies also agreed with our observations that BA was more effective at producing female flowers when treatments were begun at an early stage in flower development (Fröschle et al. 2017; Luo et al. 2020)

In contrast to the effect of BA in increasing the proportion of flowers that were female, BA had no effect on the total number of flowers and fruits. This differs from studies in other members of of flowers.

4) Combining pruning with STS and BA has additive effects on total flower and fruit numbers while maintaining high female to male ratio until the current study these treatments were not applied together. Current study showed that combining these three factors substantially improved reproductive development in cassava. While male ratio of flowers. This in turn led to greater fruit development than in each of the factors applied singly (Figure 3 and 4). STS+BA 
related to stress were over-represented compared to their frequency in the genome. These and other examples of signaling by PGRs in our study will be further discussed below. treatments with no pruning and were enriched in processes generally related to wounding (Figure 8) (Reymond et al. 2000). This is sensible since pruning involves the excision of young fork-type branches and can thus be perceived as a type of wounding response by the plant. These genes, however, had lowered expression when pruning was combined with STS+BA, the treatment combination which produced the largest number of female flowers and fruits. This suggests that wounding related genes may not be necessary for the benefit derived from pruning in flower and fruit improvement.

a) Hormone signaling: PGR treatments modulate GA and ABA signaling.

Cassava homologues of Arabidopsis Gibberellin-Insensitive Dwarf1b (GID1b and Gibberellin 2oxidase 2 (GA2ox2) were downregulated by PGR treatments (Figure 9 and 10). In some species, such as tea (Camellia sinensis) and Magnolia x soulangeana, GID genes are expressed at elevated levels when floral induction takes place (Jiang et al. 2020; Liu et al. 2020). GA2 oxidases on the other hand inactivate bioactive Gibberellins (GA) (Thomas et al. 1999). GA2ox2 has also been shown to be involved in the negative regulation of flowering time in combination with other GA2 oxidases (Rieu et al. 2008). The down regulation of GA2ox2 and GID1b genes by STS+BA suggest that treatments modulates GA signaling at the biosynthetic (i.e. GA2ox2) and the perception (i.e. GID1b) levels. Consistent with this role, studies of tree peony (Paeonia suffruticosa) showed that GID and GA2ox2 homologs had higher expression in the control buds than in buds stimulated to form flowers, and this response was interpreted to act in feedback regulation of GA synthesis (Guan et al. 2019). Insensitive 1 (ABI1) and Abscisic acid Hypersensitive Germination 1 (AHG1, also known as PP2CA) (Figure 9). These genes encode protein phosphatases that repress Abscisic acid (ABA) signaling and are sometimes expressed in circumstances where ABA signaling is being modulated (Lynch et al. 2012; Nishimura et al. 2007; Kuhn et al. 2006). Details into the role of ABA and the increase in sensitivity to ABA combined with a decrease in GA perception in cassava sex specification should be explored further. 


\section{IAA16 and TIFY10b respond to pruning}

471 The expression levels of Indoleacetic Acid-induced protein 16 (IAA16) and TIFY10b (transcriptional

472 factors with a conserved amino acid domain - TIF[F/Y]XG ) were highest in the pruning treatment,

473 without PGRs (Figure 9). This suggests a positive relationship between these hormone-signaling

474 genes and pruning (Korasick et al. 2014). The similar expression patterns of IAA16 and TIFY10b

475 suggest a possible role in cassava pruning response which should be probed further.

b) PGR and pruning treatments modulate flowering genes

478 In the current study, a group of flowering related genes were downregulated by STS+BA treatment

479 (Figure 10). These included the positive flowering effectors Histone Deacetylase 6 (HDA6), and

480 NUCLEAR FACTOR Y, SUBUNIT A1(NF-YA1), and negative flowering effectors Branched 1

481 (BRC1), and Brahma1 (BRM1, an ATP dependent chromatin remodeler). In addition to their roles in

482 flowering (Bouché et al. 2016), these genes also possess functions related to ABA response (Chen et

483 al. 2010; Peirats-Llobet et al. 2016; González-Grandío et al. 2017; Mu et al. 2013). These all had

484 similar expression patterns: they were strongly down regulated by PGR treatment. BRM1 was an

485 exception to this as it was only moderately downregulated by PGR treatment.

Among the strongly downregulated genes, the floral repressor Tempranillo 1 (TEM1),

487 functions as a downstream effector of ethylene responses and also suppresses the biosynthesis of

488 bioactive GA (Osnato et al. 2012). The downregulation of TEM1 by floral enhancing treatments in

489 this study, may reflect a role for it beyond its association with juvenility (Sgamma et al. 2013) and

490 role as a flowering repressor, possibly providing a link between repressed GA and ethylene signaling

491 (Matias-Hernandez 2014). This is reasonable given that the mode of action of STS is silver ion

492 binding to the ethylene receptor and thereby inhibiting ethylene perception (Veen 1983). 


\subsection{Conclusion}

This study showed that combining pruning, with anti-ethylene STS (supplied by petiole feeding) and cytokinin BA (sprayed to the shoot apex) significantly improved cassava female flower and fruit development. It also demonstrated that female flower enhancing treatments led to transcriptional changes indicating that the treatments repressed ethylene and GA signaling and modulated ABA signaling. Our work contributes to understanding of sex determination and to a body of evidence on hormone and signaling factors in floral development. This work also provides a flowering protocol that will facilitate cassava breeding and contribute to global food security.

\subsection{Tables}

Table 1 BA application treatment summary for Experiment I.

\begin{tabular}{|l|c|}
\hline Apical spray & Flower Developmental Stage \\
\hline Control & Spray water to shoot apex throughout time frame \\
\hline BA_Always & Spray BA beginning before flower appearance and continue until end of experiment \\
\hline BA_Early & Spray BA beginning before flower appearance and stop at flower appearance \\
\hline BA_Mid & Spray BA beginning at flower appearance and stop when first female flower antheses \\
\hline BA_Late & Spray BA beginning at 21 d after flower appearance and continue until end of experiment \\
\hline
\end{tabular}

Table 2 Summary of PGR treatments for Experiment II.

\begin{tabular}{|l|l|l|l|}
\hline PGR & BA & BA & STS \\
\hline Method of delivery: & apical spray & petiole fed & petiole fed \\
\hline
\end{tabular}




\begin{tabular}{|l|l|l|l|}
\hline Treatment name: & & & \\
\hline Control & & & \\
\hline BA & $x$ & & \\
\hline BA+BA & $x$ & $x$ & \\
\hline STS+BA & $x$ & $x$ & $x$ \\
\hline STS+BA+BA & $x$ & $x$ & $x$ \\
\hline
\end{tabular}

5095 Conflict of Interest

510 The authors declare that the research was conducted in the absence of any commercial or financial

511 relationships that could be construed as a potential conflict of interest.

\section{Author Contributions}

513 D.O, P.K and T.S obtained funding. D.O and T.S designed experiment. P.K supervised work on field

514 in Nigeria. D.O, O.E and P.H conducted field and controlled condition experiments. D.O analysed

515 data. D.O, O.E, P.H, P.K, T.S wrote manuscript.

\section{$516 \quad 7 \quad$ Funding}

517 Funding for this work was obtained from the Federal government of Nigeria and the "NextGen

518 Cassava Breeding Project," through funding from the Bill \& Melinda Gates Foundation and the

519 UKAID

\section{Acknowledgments}

521 The authors would also like to thank the Federal Government of Nigeria for partly funding Deborah's

522 studies through the Presidential Special Scholarship for Innovation and Development (PRESSID)

523 managed by the National Universities Commission (NUC) and funded by the Federal Scholarship

524 Board (FSB). The authors would also like to thank the Bioscience unit and Cassava Breeding unit of 
525 the International Institute of Tropical Agriculture, Nigeria for providing laboratory facilities, office

526 space and field space for conducting experiments.

528 This research was part of the Ph.D. dissertation of the first author at Cornell University, Ithaca, NY

5309 References

531 Adeyemo OS, Chavarriaga P, Tohme J, Fregene M, Davis SJ, Setter TL (2017) Overexpression of 532 Arabidopsis FLOWERING LOCUS T (FT) gene improves floral development in cassava (Manihot 533 esculenta, Crantz). Plos One 12 (7):e0181460

534 Adeyemo OS, Hyde PT, Setter TL (2019) Identification of FT family genes that respond to 535 photoperiod, temperature and genotype in relation to flowering in cassava (Manihot esculenta, 536 Crantz). Plant reproduction 32 (2):181-191

537 An J, Almasaud RA, Bouzayen M, Zouine M, Chervin C (2020) Auxin and ethylene regulation of 538 fruit set. Plant Sci 292:110381

539 Bouché F, Lobet G, Tocquin P, Périlleux C (2016) FLOR-ID: an interactive database of flowering540 time gene networks in Arabidopsis thaliana. Nucleic Acids Research 44 (D1):D1167-D1171

541 Brooks ME, Kristensen K, van Benthem KJ, Magnusson A, Berg CW, Nielsen A, Skaug HJ, Machler 542 M, Bolker BM (2017) glmmTMB balances speed and flexibility among packages for zero-inflated 543 generalized linear mixed modeling. The R journal 9 (2):378-400

544 Bull SE, Alder A, Barsan C, Kohler M, Hennig L, Gruissem W, Vanderschuren H (2017)

545 FLOWERING LOCUS T triggers early and fertile flowering in glasshouse cassava (Manihot 546 esculenta Crantz). Plants 6 (2):22

547 Carbonell-Bejerano P, Urbez C, Granell A, Carbonell J, Perez-Amador MA (2011) Ethylene is

548 involved in pistil fate by modulating the onset of ovule senescence and the GA-mediated fruit set in 549 Arabidopsis. Bmc Plant Biol 11 (1):84

550 Ceballos H, Iglesias CA, Perez JC, Dixon AG (2004) Cassava breeding: opportunities and 551 challenges. Plant Mol Biol 56 (4):503-516 
552 Ceballos H, Pérez JC, Joaqui Barandica O, Lenis JI, Morante N, Calle F, Pino L, Hershey CH (2016)

553 Cassava breeding I: The value of breeding value. Front Plant Sci 7:1227

554 Chen L-T, Luo M, Wang Y-Y, Wu K (2010) Involvement of Arabidopsi s histone deacetylase HDA6 555 in ABA and salt stress response. J Exp Bot 61 (12):3345-3353

556 Chen M-S, Pan B-Z, Wang G-J, Ni J, Niu L, Xu Z-F (2014) Analysis of the transcriptional responses

557 in inflorescence buds of Jatropha curcasexposed to cytokinin treatment. Bmc Plant Biol 14 (1):318

558 De Souza AP, Long SP (2018) Toward improving photosynthesis in cassava: characterizing

559 photosynthetic limitations in four current African cultivars. Food and energy security 7 (2):e00130

560 Den Nijs A, Visser D (1980) Induction of male flowering in gynoecious cucumbers (Cucumis sativus

561 L.) by silver ions. Euphytica 29 (2):273-280

562 Dennis G, Sherman BT, Hosack DA, Yang J, Gao W, Lane HC, Lempicki RA (2003) DAVID:

563 database for annotation, visualization, and integrated discovery. Genome biology 4 (9):1-11

564 Fröschle M, Horn H, Spring O (2017) Effects of the cytokinins 6-benzyladenine and forchlorfenuron

565 on fruit-, seed-and yield parameters according to developmental stages of flowers of the biofuel plant

566 Jatropha curcas L.(Euphorbiaceae). Plant Growth Regul 81 (2):293-303

567 Fu Q, Niu L, Zhang Q, Pan B-Z, He H, Xu Z-F (2014) Benzyladenine treatment promotes floral

568 feminization and fruiting in a promising oilseed crop Plukenetia volubilis. Industrial Crops and

569 Products 59:295-298

570 Ge SX, Jung D, Yao R (2020) ShinyGO: a graphical gene-set enrichment tool for animals and plants.

571 Bioinformatics $36(8): 2628-2629$

572 Giovannoni JJ (2004) Genetic regulation of fruit development and ripening. The plant cell 16 (suppl

573 1):S170-S180

574 González-Grandío E, Pajoro A, Franco-Zorrilla JM, Tarancón C, Immink RG, Cubas P (2017)

575 Abscisic acid signaling is controlled by a BRANCHED1/HD-ZIP I cascade in Arabidopsis axillary

576 buds. Proceedings of the National Academy of Sciences 114 (2):E245-E254 
577 Goodstein DM, Shu S, Howson R, Neupane R, Hayes RD, Fazo J, Mitros T, Dirks W, Hellsten U,

578 Putnam N (2012) Phytozome: a comparative platform for green plant genomics. Nucleic acids

579 research $40(\mathrm{D} 1): \mathrm{D} 1178-\mathrm{D} 1186$

580 Guan Y.R, Xue J.Q, Xue Y.Q, Yang R.W, Wang S.L, Zhang X.X (2019) Effect of exogenous GA3

581 on flowering quality, endogenous hormones, and hormone-and flowering-associated gene expression

582 in forcing-cultured tree peony (Paeonia suffruticosa). Journal of Integrative Agriculture 18 (6):1295-

$583 \quad 1311$

584 Halsey ME, Olsen KM, Taylor NJ, Chavarriaga $\square$ Aguirre P (2008) Reproductive biology of cassava

585 (Manihot esculenta Crantz) and isolation of experimental field trials. Crop Sci 48 (1):49-58

586 Horn JW, van Ee BW, Morawetz JJ, Riina R, Steinmann VW, Berry PE, Wurdack KJ (2012)

587 Phylogenetics and the evolution of major structural characters in the giant genus Euphorbia

588 L.(Euphorbiaceae). Molecular Phylogenetics and Evolution 63 (2):305-326

589 Hyde PT, Guan X, Abreu V, Setter TL (2020) The anti-ethylene growth regulator silver thiosulfate

590 (STS) increases flower production and longevity in cassava (Manihot esculenta Crantz). Plant

591 Growth Regul 90 (3):441-453

592 Iragaba P (2019) Translating Cassava Attributes Preferred by Ugandan Smallholder Farmers into

593 Breeding Targets. Cornell University,

594 Jiang Z, Sun L, Wei Q, Ju Y, Zou X, Wan X, Liu X, Yin Z (2020) A New Insight into Flowering

595 Regulation: Molecular Basis of Flowering Initiation in Magnoliax soulangeana 'Changchun'. Genes

$59611(1): 15$

597 Kanrar S, Bhattacharya M, Arthur B, Courtier J, Smith HM (2008) Regulatory networks that function

598 to specify flower meristems require the function of homeobox genes PENNYWISE and

599 POUND $\square$ FOOLISH in Arabidopsis. The Plant Journal 54 (5):924-937

600 Korasick DA, Westfall CS, Lee SG, Nanao MH, Dumas R, Hagen G, Guilfoyle TJ, Jez JM, Strader

601 LC (2014) Molecular basis for AUXIN RESPONSE FACTOR protein interaction and the control of

602 auxin response repression. Proceedings of the National Academy of Sciences 111 (14):5427-5432 
603 Kuhn JM, Boisson-Dernier A, Dizon MB, Maktabi MH, Schroeder JI (2006) The protein

604 phosphatase AtPP2CA negatively regulates abscisic acid signal transduction in Arabidopsis, and

605 effects of abh1 on AtPP2CA mRNA. Plant Physiol 140 (1):127-139

606 Lenth R (2019) emmeans: Estimated marginal means, aka least-squares means. R package version

607 1.4. 3.01.

608 Li S, Cui Y, Zhou Y, Luo Z, Liu J, Zhao M (2017) The industrial applications of cassava: current

609 status, opportunities and prospects. Journal of the Science of Food and Agriculture 97 (8):2282-2290

610 Lin Y-H, Lin M-H, Gresshoff PM, Ferguson BJ (2011) An efficient petiole-feeding bioassay for

611 introducing aqueous solutions into dicotyledonous plants. Nature Protocols 6 (1):36-45

612 Liu Q, Liu J, Zhang P, He S (2014) Root and tuber crops.

613 Liu X, Hou X (2018) Antagonistic regulation of ABA and GA in metabolism and signaling

614 pathways. Front Plant Sci 9:251

615 Liu Y, Hao X, Lu Q, Zhang W, Zhang H, Wang L, Yang Y, Xiao B, Wang X (2020) Genome-wide

616 identification and expression analysis of flowering-related genes reveal putative floral induction and

617 differentiation mechanisms in tea plant (Camellia sinensis). Genomics

618 Love MI, Huber W, Anders S (2014) Moderated estimation of fold change and dispersion for RNA-

619 seq data with DESeq2. Genome biology 15 (12):550

620 Luo Y, Pan B-Z, Li L, Yang C-X, Xu Z-F (2020) Developmental basis for flower sex determination

621 and effects of cytokinin on sex determination in Plukenetia volubilis (Euphorbiaceae). Plant

622 Reproduction:1-14

623 Lynch T, Erickson BJ, Finkelstein RR (2012) Direct interactions of ABA-insensitive (ABI)-clade

624 protein phosphatase (PP) 2Cs with calcium-dependent protein kinases and ABA response element-

625 binding bZIPs may contribute to turning off ABA response. Plant Mol Biol 80 (6):647-658

626 Martínez C, Manzano S, Megías Z, Garrido D, Picó B, Jamilena M (2013) Involvement of ethylene

627 biosynthesis and signalling in fruit set and early fruit development in zucchini squash (Cucurbita

628 pepo L.). Bmc Plant Biol 13 (1):139 
629 Matias-Hernandez L. 2014. RAV genes: regulation of floral induction and beyond. Annals of Botany

630 (London) 114, 1459-1470.

631 Mishra NS, Tuteja R, Tuteja N (2006) Signaling through MAP kinase networks in plants. Archives of 632 Biochemistry and Biophysics $452(1): 55-68$

633 Moormann F, Lal R, Juo A (1975) The soils of IITA, IITA Technical Bulletin No. 3. IITA, Ibadan

634 Mu J, Tan H, Hong S, Liang Y, Zuo J (2013) Arabidopsis transcription factor genes NF-YA1, 5, 6, 635 and 9 play redundant roles in male gametogenesis, embryogenesis, and seed development. Mol Plant $636 \quad 6(1): 188-201$

637 Nassar NM (1980) Attempts to hybridize wildManihot species with cassava. Economic Botany 34 $638 \quad(1): 13-15$

639 Nishimura N, Yoshida T, Kitahata N, Asami T, Shinozaki K, Hirayama T (2007)

$640 \mathrm{ABA} \square$ Hypersensitive Germination1 encodes a protein phosphatase 2C, an essential component of 641 abscisic acid signaling in Arabidopsis seed. The Plant Journal 50 (6):935-949

642 Odipio J, Getu B, Chauhan R, Alicai T, Bart R, Nusinow DA, Taylor NJ (2020) Transgenic 643 overexpression of endogenous FLOWERING LOCUS T-like gene MeFT1 produces early flowering 644 in cassava. Plos One 15 (1):e0227199

645 Onai K, Ishiura M (2005) PHYTOCLOCK 1 encoding a novel GARP protein essential for the 646 Arabidopsis circadian clock. Genes to Cells 10 (10):963-972

647 Orzáez D, Granell A (1997) DNA fragmentation is regulated by ethylene during carpel senescence in 648 Pisum sativum. The Plant Journal 11 (1):137-144

649 Osnato M, Castillejo C, Matías-Hernández L, Pelaz S (2012) TEMPRANILLO genes link 650 photoperiod and gibberellin pathways to control flowering in Arabidopsis. Nat Commun 3 (1):1-8

651 Pan B-Z, Chen M-S, Ni J, Xu Z-F (2014) Transcriptome of the inflorescence meristems of the 652 biofuel plant Jatropha curcas treated with cytokinin. BMC genomics 15 (1):974

653 Pan B-Z, Xu Z-F (2011) Benzyladenine treatment significantly increases the seed yield of the biofuel 654 plant Jatropha curcas. J Plant Growth Regul 30 (2):166-174 
655 Pech JC, Purgatto E, Bouzayen M, Latché A (2018) Ethylene and fruit ripening. Annual Plant

656 Reviews online:275-304

657 Peirats-Llobet M, Han S-K, Gonzalez-Guzman M, Jeong CW, Rodriguez L, Belda-Palazon B,

658 Wagner D, Rodriguez PL (2016) A direct link between abscisic acid sensing and the chromatin-

659 remodeling ATPase BRAHMA via core ABA signaling pathway components. Mol Plant 9 (1):136-

$660 \quad 147$

661 Perera PI, Quintero M, Dedicova B, Kularatne J, Ceballos H (2013) Comparative morphology,

662 biology and histology of reproductive development in three lines of Manihot esculenta Crantz

663 (Euphorbiaceae: Crotonoideae). Aob Plants 5

664 Pineda LM, Yu B, Tian Y, Morante N, Salazar S, Hyde P, Setter TL, Ceballos H. 2020. Effect of

665 pruning young branches on fruit and seed set in cassava. Frontiers in Plant Science 11, 1107.

666 Ram HM, Sett R (1982) Induction of fertile male flowers in genetically female Cannabis sativa plants

667 by silver nitrate and silver thiosulphate anionic complex. Theor Appl Genet 62 (4):369-375

668 Reymond P, Weber H, Damond M, Farmer EE. 2000. Differential Gene Expression in Response to

669 Mechanical Wounding and Insect Feeding in Arabidopsis Plant Cell 12, 707-720.

670 Rieu I, Eriksson S, Powers SJ, Gong F, Griffiths J, Woolley L, Benlloch R, Nilsson O, Thomas SG,

671 Hedden P (2008) Genetic analysis reveals that C19-GA 2-oxidation is a major gibberellin

672 inactivation pathway in Arabidopsis. The Plant Cell 20 (9):2420-2436

673 Rife TW, Poland JA (2014) Field Book: An open $\square$ source application for field data collection on

674 Android. Crop Science 54 (4):1624-1627

675 Serek M, Woltering EJ, Sisler EC, Frello S, Sriskandarajah S. 2006. Controlling ethylene responses

676 in flowers at the receptor level. Biotechnology Advances 24, 368-381.

677 Sgamma T, Jackson A, Muleo R, Thomas B, Massiah A. 2014. TEMPRANILLO is a regulator of 678 juvenility in plants. Scientific Reports 4, 3704.

679 Sonnewald U, Fernie AR, Gruissem W, Schläpfer P, Anjanappa RB, Chang SH, Ludewig F, Rascher

680 U, Muller O, van Doorn AM (2020) The Cassava Source $\square$ Sink project: Opportunities and challenges

681 for crop improvement by metabolic engineering. The Plant Journal 
682 Souza LS, Alves AAC, de Oliveira EJ (2020) Phenological diversity of flowering and fruiting in

683 cassava germplasm. Sci Hortic-Amsterdam 265:109253

684 Team RC (2013) R: A language and environment for statistical computing.

685 Theißen G, Melzer R, Rümpler F (2016) MADS-domain transcription factors and the floral quartet

686 model of flower development: linking plant development and evolution. Development 143

$687 \quad(18): 3259-3271$

688 Thomas SG, Phillips AL, Hedden P (1999) Molecular cloning and functional expression of 689 gibberellin 2-oxidases, multifunctional enzymes involved in gibberellin deactivation. Proceedings of 690 the National Academy of Sciences 96 (8):4698-4703

691 Tuteja N, Gill SS, Tiburcio AF, Tuteja R (2012) Improving crop resistance to abiotic stress. John 692 Wiley \& Sons,

693 Vanholme B, Grunewald W, Bateman A, Kohchi T, Gheysen G (2007) The tify family previously 694 known as ZIM. Trends Plant Sci 12 (6):239-244

695 Veen H (1983) Silver thiosulphate: an experimental tool in plant science. Sci Hortic-Amsterdam 20 696 (3):211-224

697 Wolfe MD, Del Carpio DP, Alabi O, Ezenwaka LC, Ikeogu UN, Kayondo IS, Lozano R, Okeke UG, 698 Ozimati AA, Williams E (2017) Prospects for genomic selection in cassava breeding. The Plant 699 Genome $10(3): 1-19$

700 Yang C-H, Chou M-L (1999) FLD interacts with CO to affect both flowering time and floral

701 initiation in Arabidopsis thaliana. Plant Cell Physiol 40 (6):647-650

702 Zheng Y, Jiao C, Sun H, Rosli HG, Pombo MA, Zhang P, Banf M, Dai X, Martin GB, Giovannoni JJ 703 (2016) iTAK: a program for genome-wide prediction and classification of plant transcription factors, 704 transcriptional regulators, and protein kinases. Mol Plant 9 (12):1667-1670 
bioRxiv preprint doi: https://doi.org/10.1101/2020.12.15.422940; this version posted December 22, 2020. The copyright holder for this preprint (which was not certified by peer review) is the author/funder, who has granted bioRxiv a license to display the preprint in perpetuity. It is made available under aCC-BY 4.0 International license.
a)
b)
c)

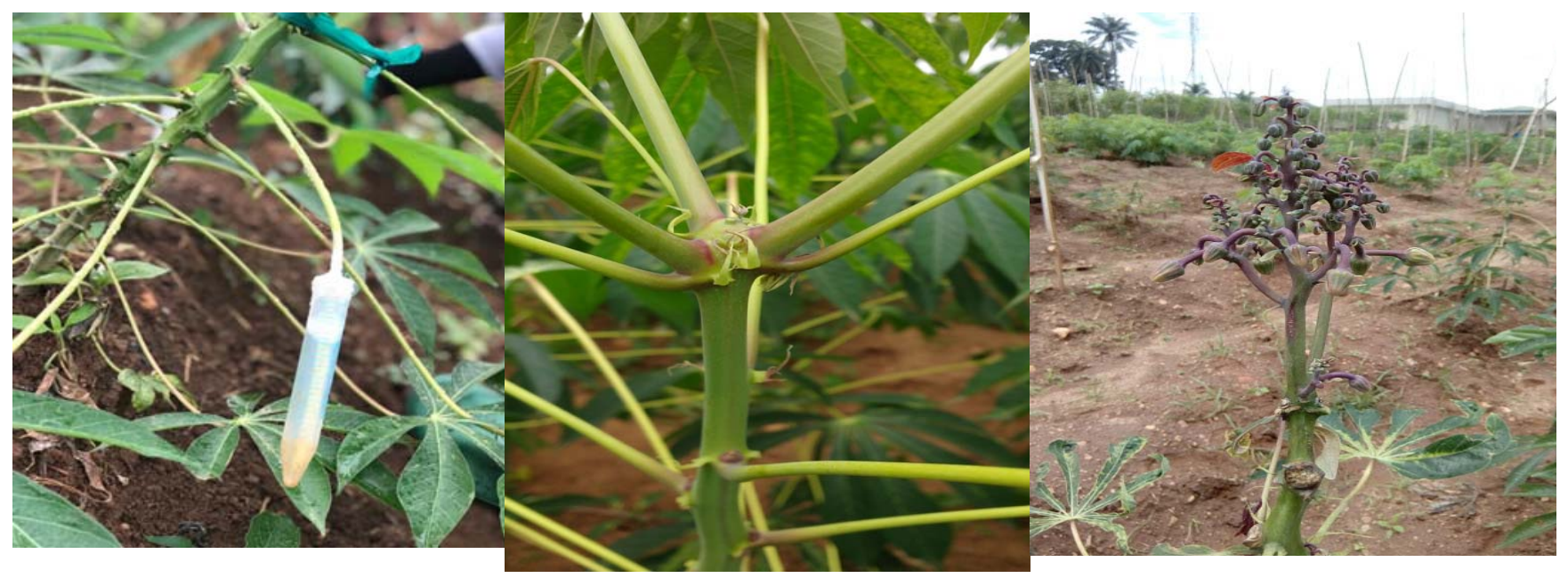

707 Figure1 Photos of cassava a) receiving treatment by petiole feeding b) with unpruned fork-type

708 branches; inflorescence aborting c) pruned fork-type branches with thriving flowers

709

710

a)

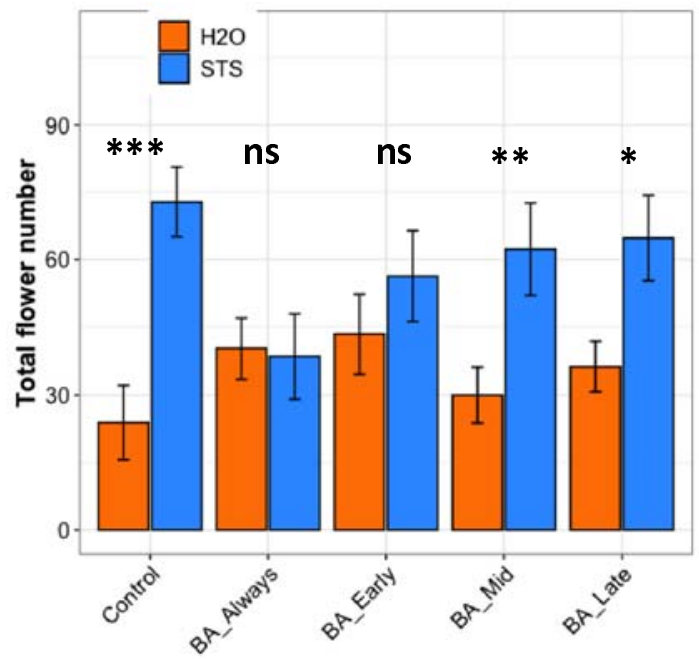

c) b)

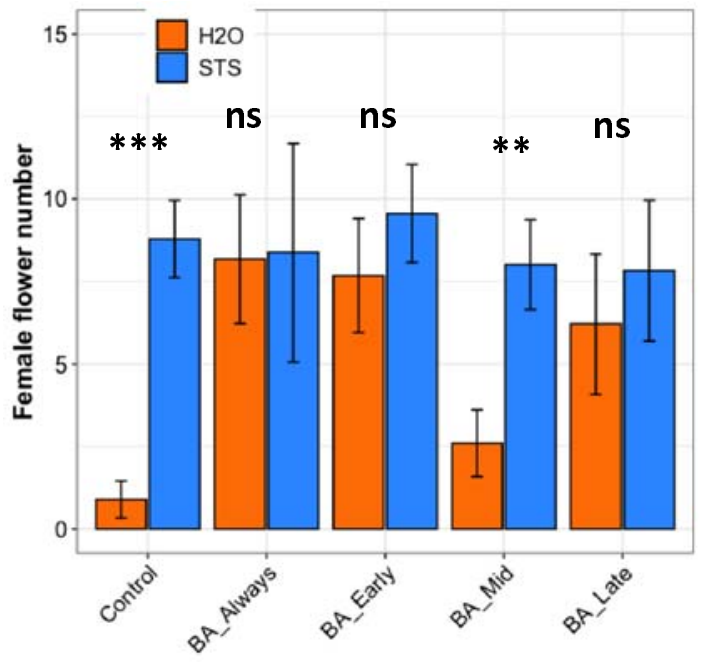

d) 

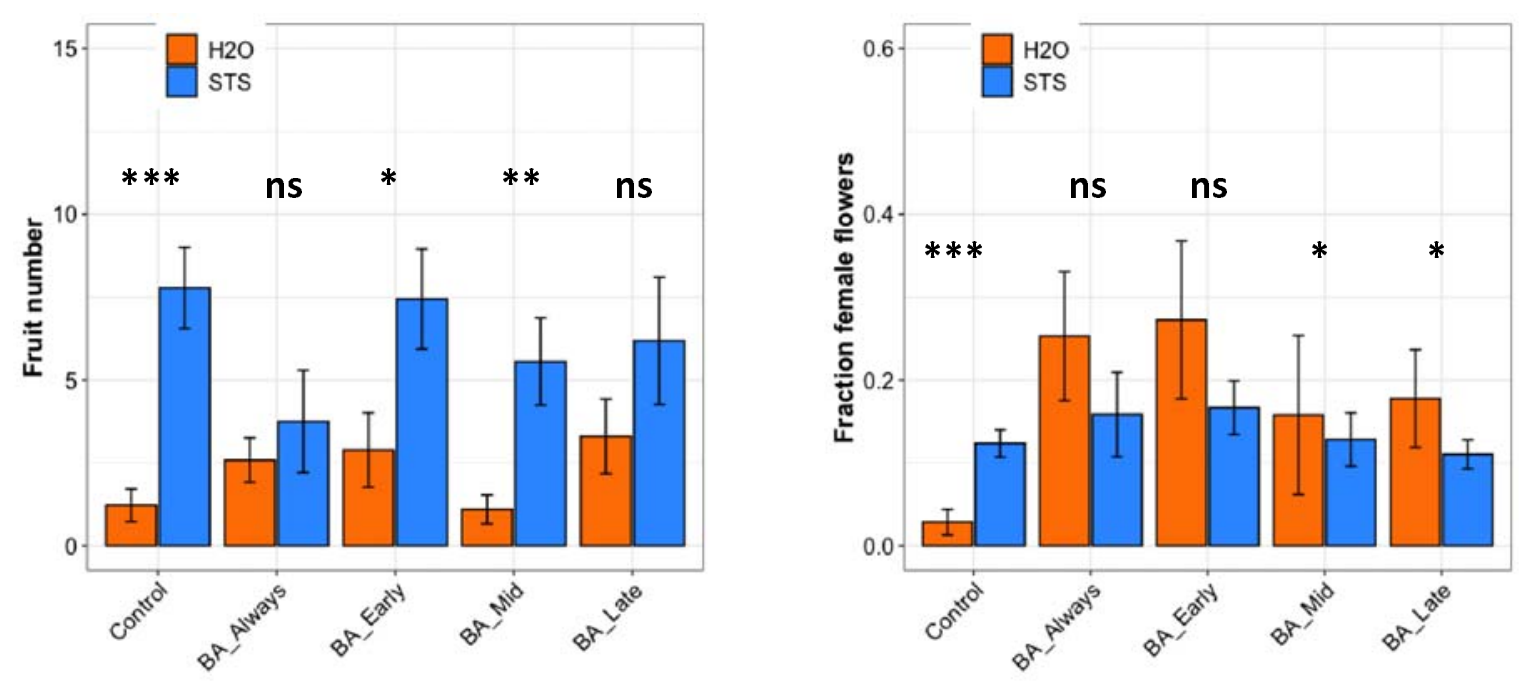

711 Figure 2 Effect of STS and BA treatments on: a) total flower numbers per plant, b) number of

712 female flowers per plant, c) number of fruit per plant, and d) fraction of female flowers. STS versus

713 no-STS $\left(\mathrm{H}_{2} \mathrm{O}\right)$ treatment is indicated by bar color as shown in the legends. BA treatments were

714 applied thoughout floral development (BA_Always), or they were initiated at three timings

715 (BA_Early, BA_Mid, or BA_Late). The study was conducted using genotype IITA-TMS-I980002 in

716 the field at Ibadan, Nigeria in 2017. See M\&M Section for details. Data shown is the mean \pm SE of

71710 replicates; asterisk indicate statistical significance in a pairwise comparison between + STS and no

718 STS; $\mathrm{P}<0.05$ (*), $\mathrm{P}<0.01(* *), \mathrm{P}<0.001(* * *)$. 
a)

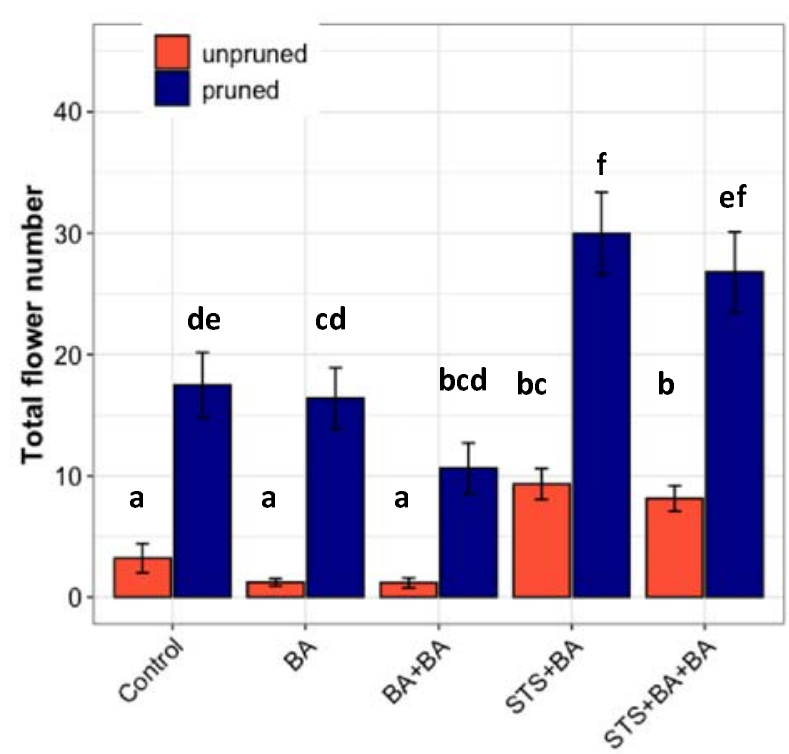

c)

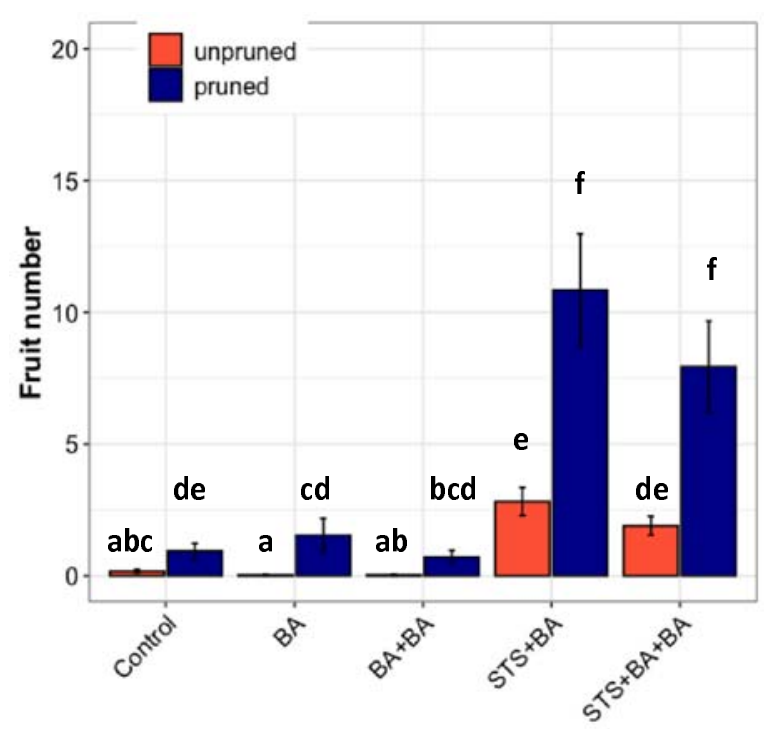

b)

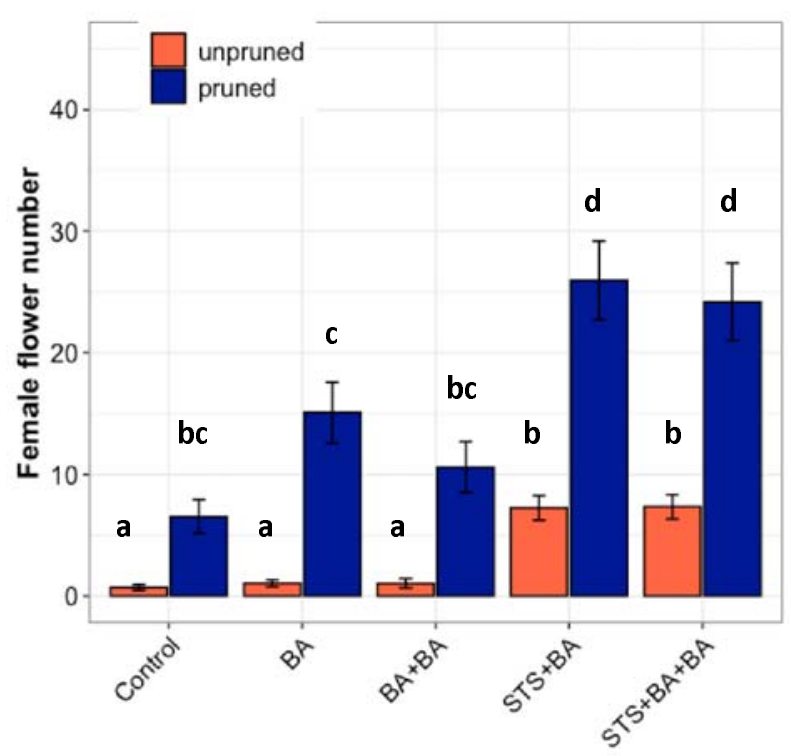

d)

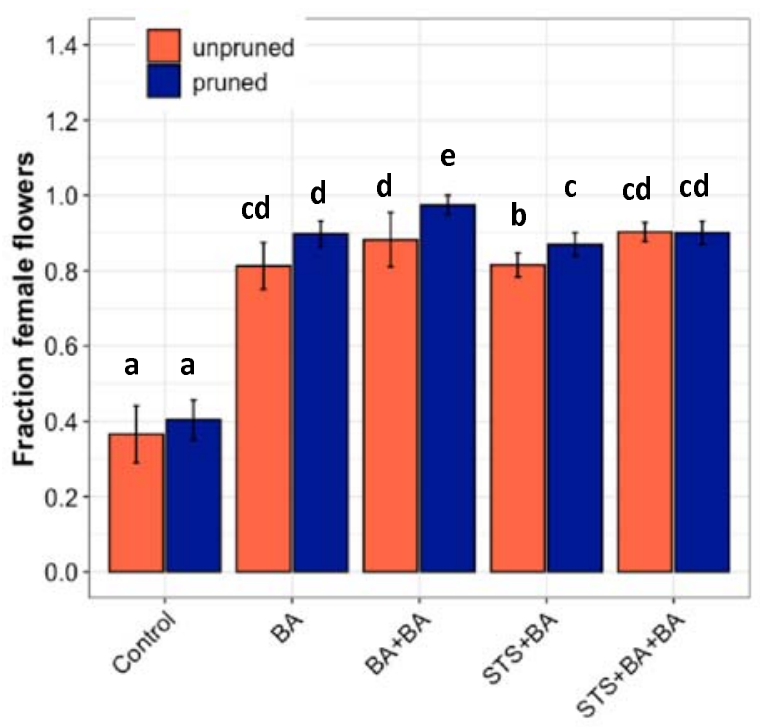

720 Figure 3 The effect of PGRs and pruning on flower development. a) Total flowers, b) female flower

721 numbers c) fruit numbers d) proportion of female flowers (reflecting only plants with at least one

722 flower). Data shown is the mean of studies conducted in two years (2018 and 2019), each with 6

723 blocks containing all treatments and 8 (2018) or 4 (2019) plants as experimental units. Treatments

724 with different lowercase letters are significantly $(\mathrm{P}<0.05)$ different using Tukey's HSD test. 
a)

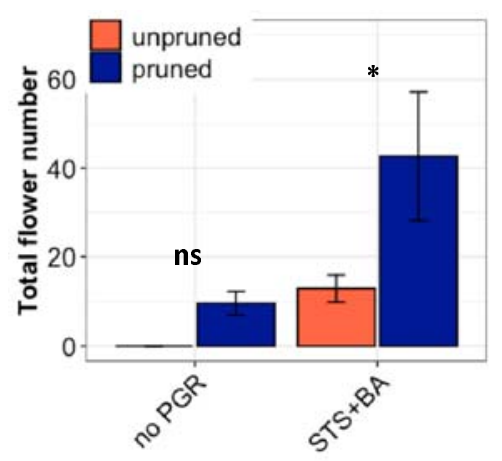

b)

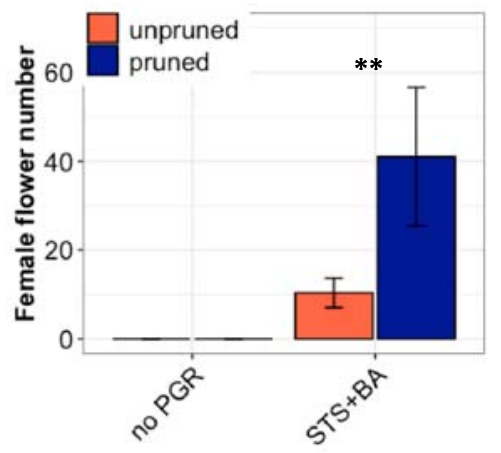

c)

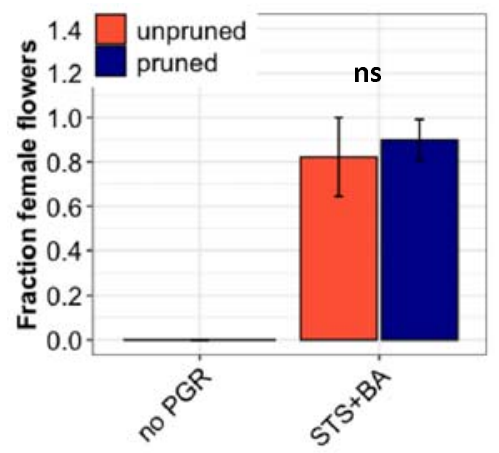

725 Figure 4The effect of PGRs (combined STS+BA) and pruning on flower development under

726 greenhouse conditions. a) total flowers, b) female flowers, and c) proportion of female flowers. Data

727 shown is the mean 3 plants per treatment per pruning level for the genotype 0002. * indicates

728 statistical significance on a pairwise comparison of pruned versus unpruned $(\mathrm{P}<0.05)$.

729

730

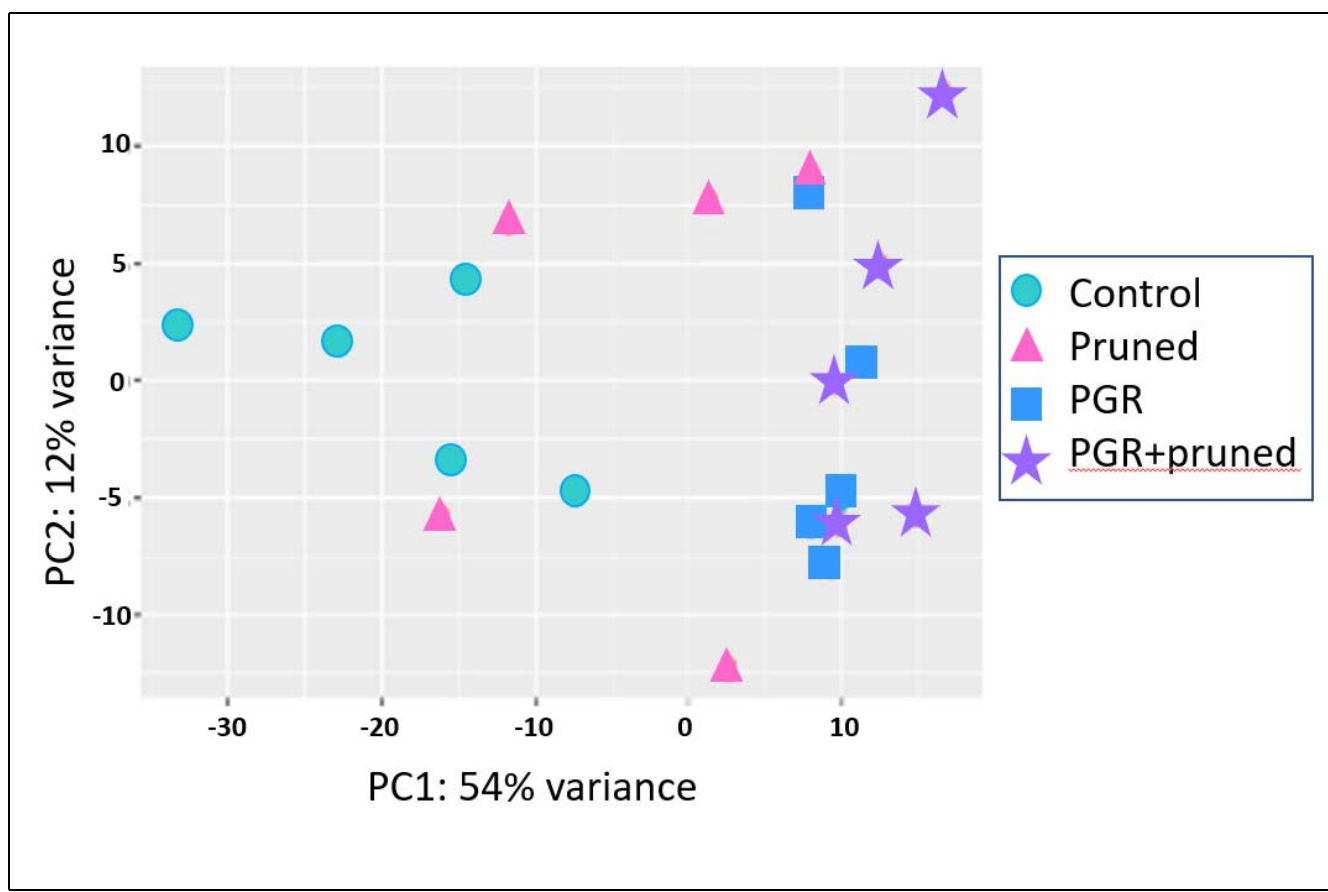

731 Figure 5 Comparison of differentially expressed genes (DEGs) by PCA with respect to treatments 


\section{a) Enriched KEGG pathways among PGR- upregulated genes}

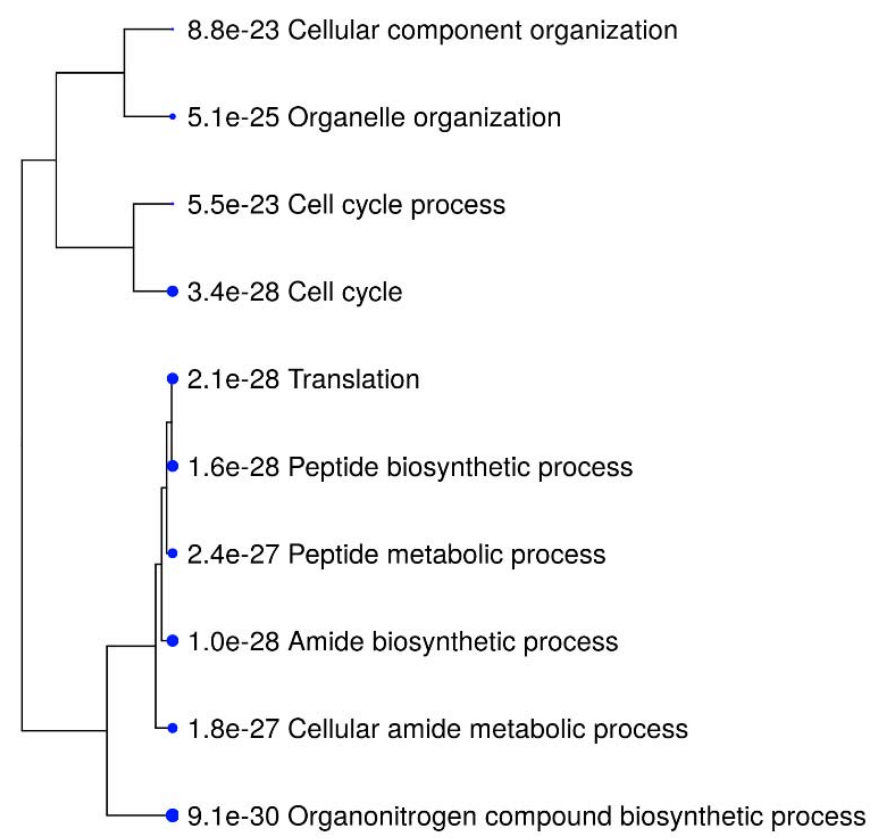

\section{b) Enriched KEGG pathways among PGR-down regulated genes}

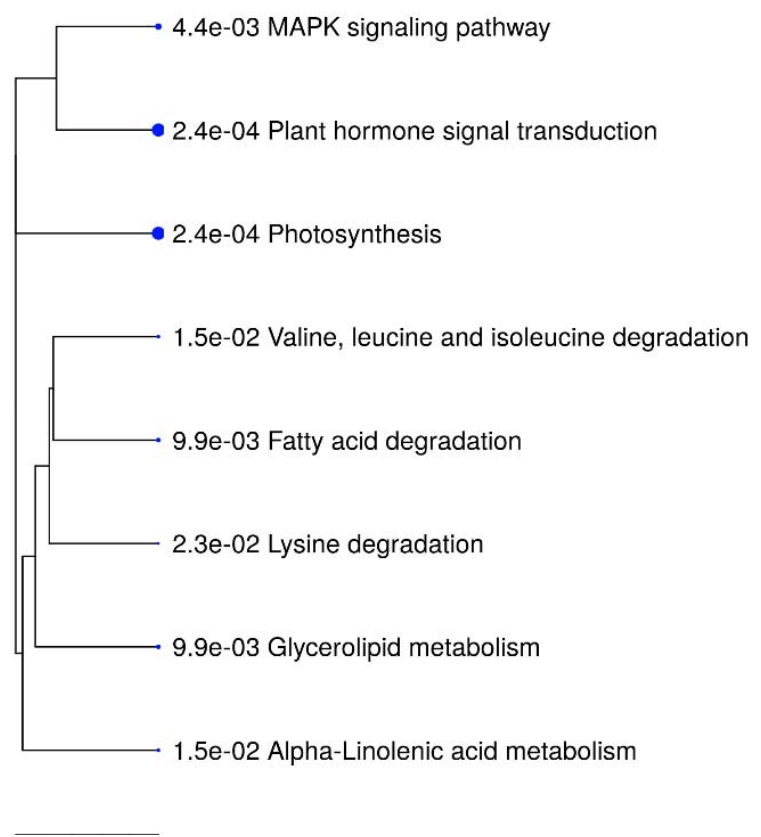

734 Figure 6 Top ten KEGG pathway enrichment terms for up-regulated and down-regulated genes in

735 PGR-treated versus control comparison. Categories of differentially expressed genes which were

736 significantly enriched relative to the Arabidopsis genome ( $\mathrm{p}$-values shown): 
bioRxiv preprint doi: https://doi.org/10.1101/2020.12.15.422940; this version posted December 22, 2020. The copyright holder for this preprint (which was not certified by peer review) is the author/funder, who has granted bioRxiv a license to display the preprint in perpetuity. It is made available under aCC-BY 4.0 International license.

a)

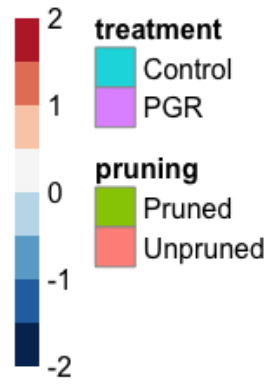

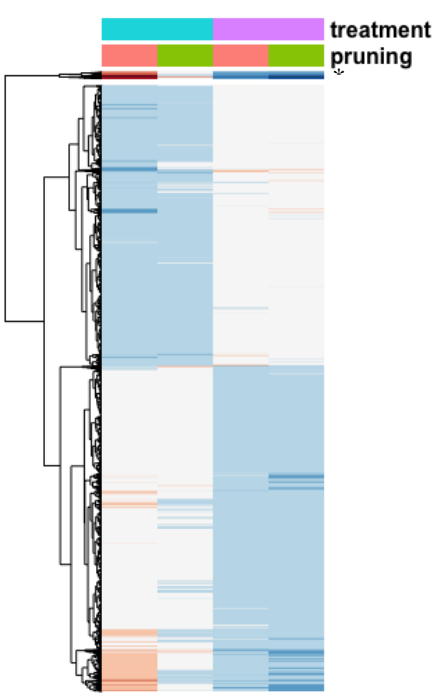

c)

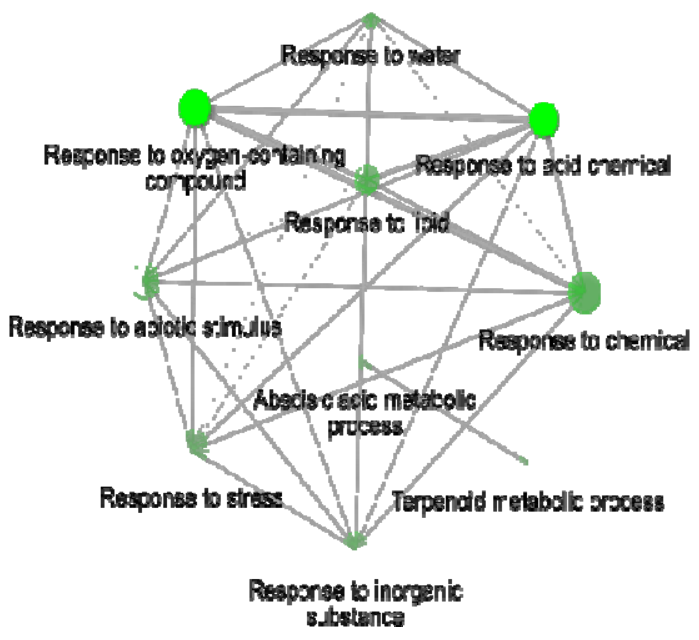

b) 
bioRxiv preprint doi: https://doi.org/10.1101/2020.12.15.422940; this version posted December 22, 2020. The copyright holder for this preprint (which was not certified by peer review) is the author/funder, who has granted bioRxiv a license to display the preprint in perpetuity. It is made available under aCC-BY 4.0 International license.

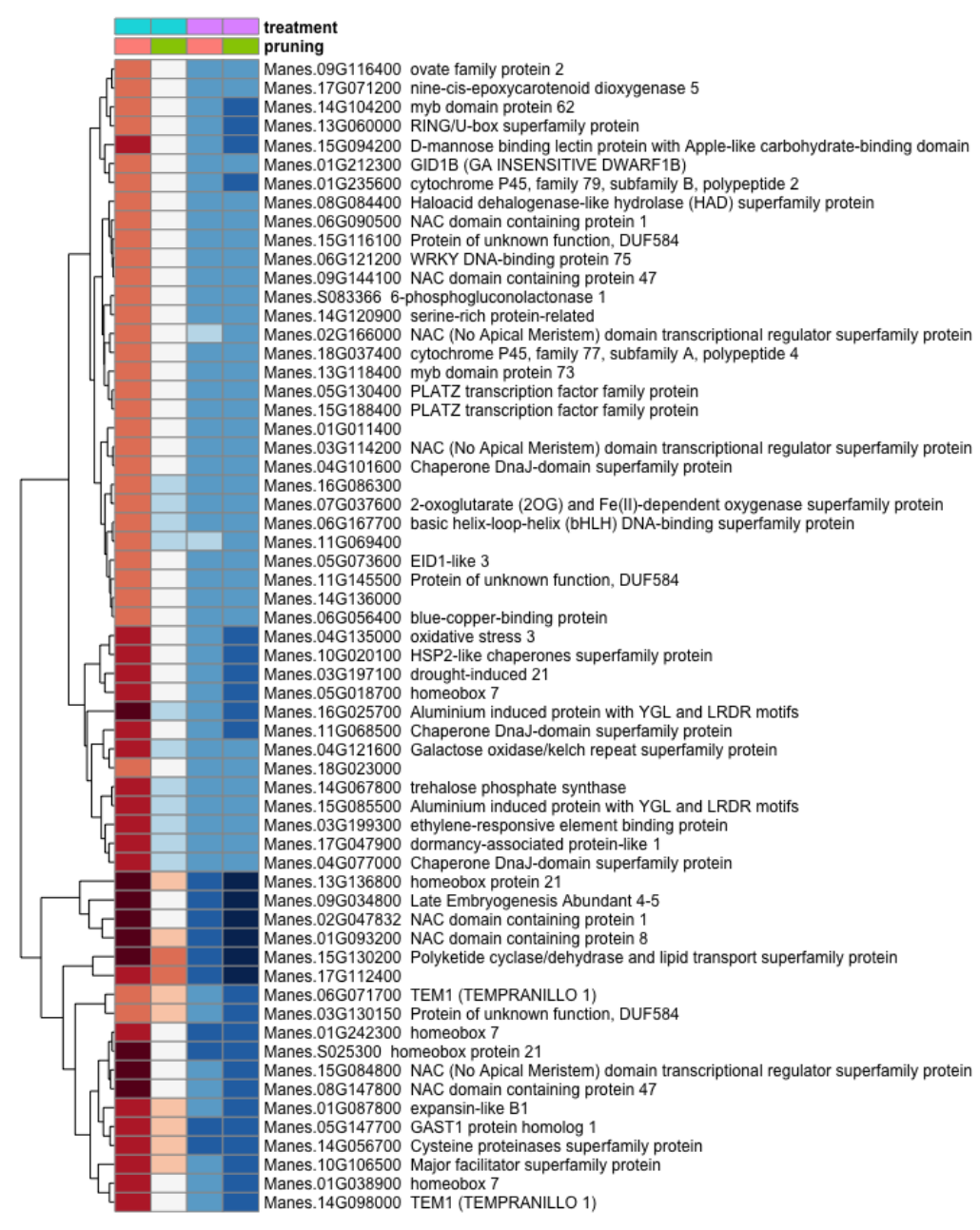

738 Figure 7 Differentially expressed genes in response to PGRs and pruning. Colors indicate fold 739 change ( $\log _{2}$ scale shown). a) Full complement of DEGs b) Uppermost slice (*) c) Enrichment analysis of the gene cluster $(*)$ 
bioRxiv preprint doi: https://doi.org/10.1101/2020.12.15.422940; this version posted December 22, 2020. The copyright holder for this preprint (which was not certified by peer review) is the author/funder, who has granted bioRxiv a license to display the preprint in perpetuity. It is made available under aCC-BY 4.0 International license.

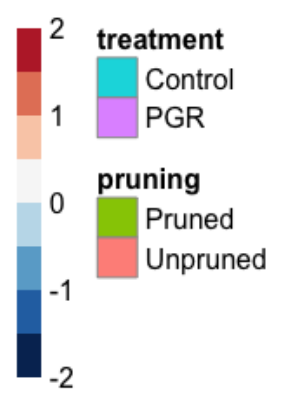

a)

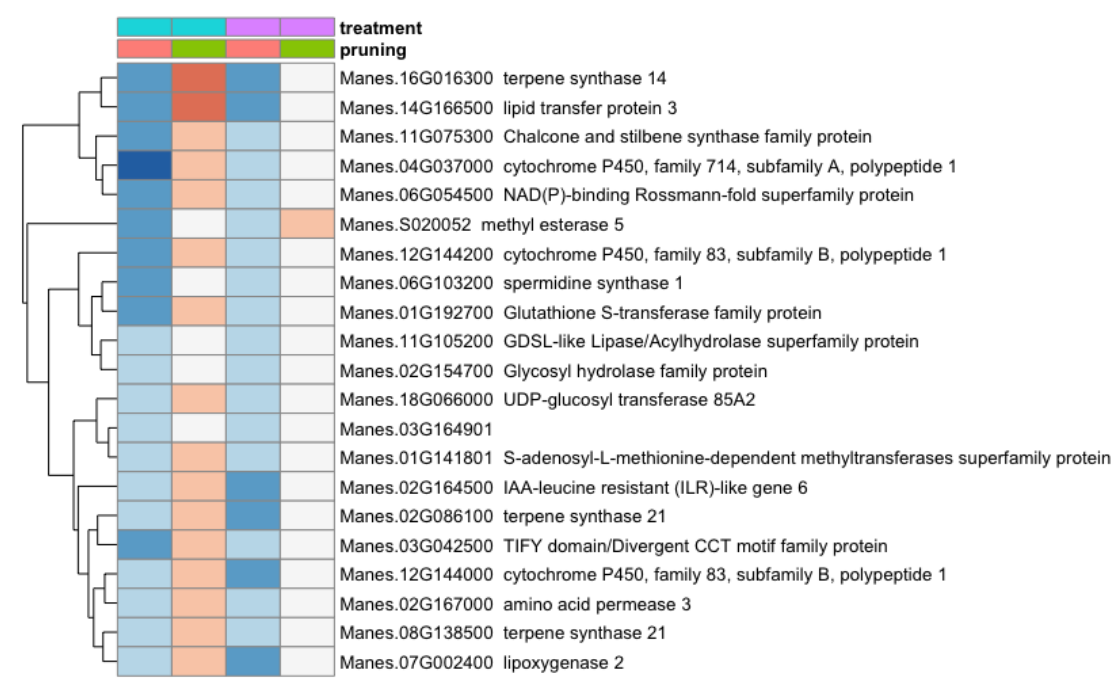

b)

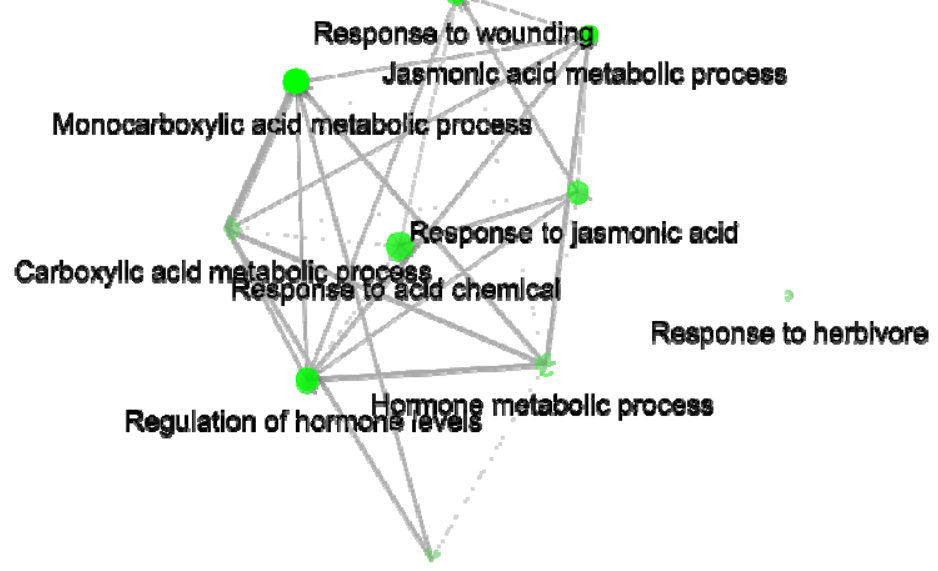

Monocarboxylic acid blosynthetic process

741 Figure 8 a and b. (a. top panel) differentially expressed genes identified as statistically significant in 742 response to pruning only. (b. lower panel): Enrichment analysis of pruning responsive genes. Colors 743 indicate fold change ( $\log _{2}$ scale shown). 
bioRxiv preprint doi: https://doi.org/10.1101/2020.12.15.422940; this version posted December 22, 2020. The copyright holder for this preprint (which was not certified by peer review) is the author/funder, who has granted bioRxiv a license to display the preprint in perpetuity. It is made available under aCC-BY 4.0 International license.

a) All hormone signaling genes DE

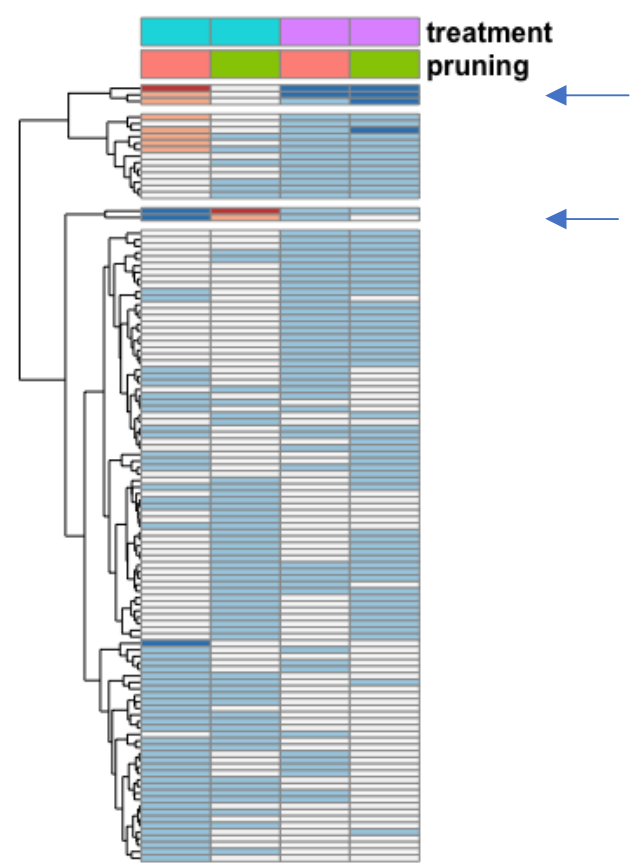

b) Cluster 1 in detail

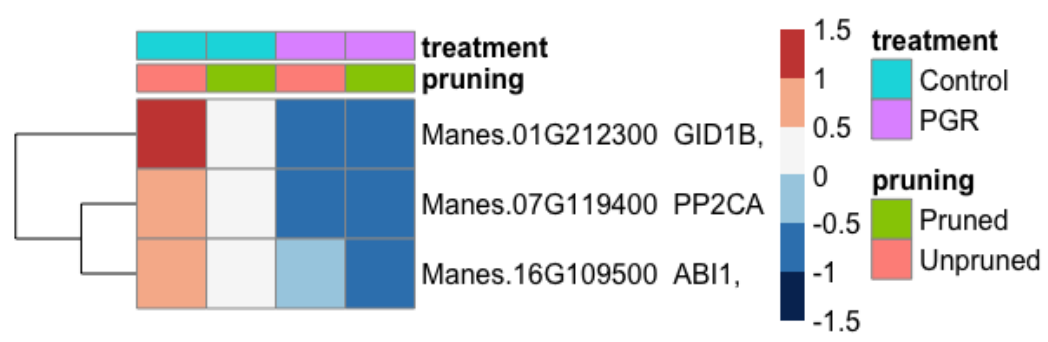

c) Cluster 2 in detail

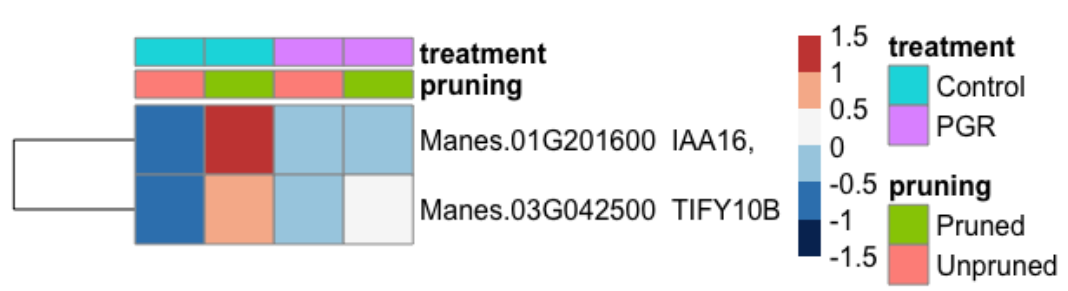

745 Figure 9 Differentially expressed hormone-signaling genes in response to PGR and pruning (a),

746 Clusters of highly affected genes are shown in b) and c). 
bioRxiv preprint doi: https://doi.org/10.1101/2020.12.15.422940; this version posted December 22, 2020. The copyright holder for this preprint (which was not certified by peer review) is the author/funder, who has granted bioRxiv a license to display the preprint in perpetuity. It is made available under aCC-BY 4.0 International license.

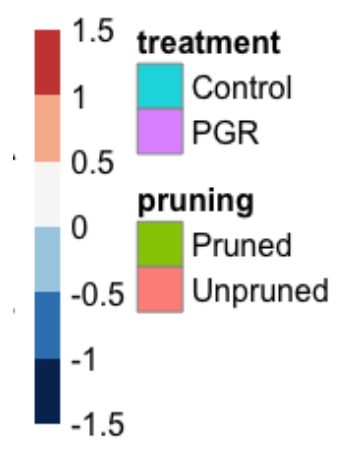

a) All known flowering genes which were differentially expressed in response to PGR or pruning

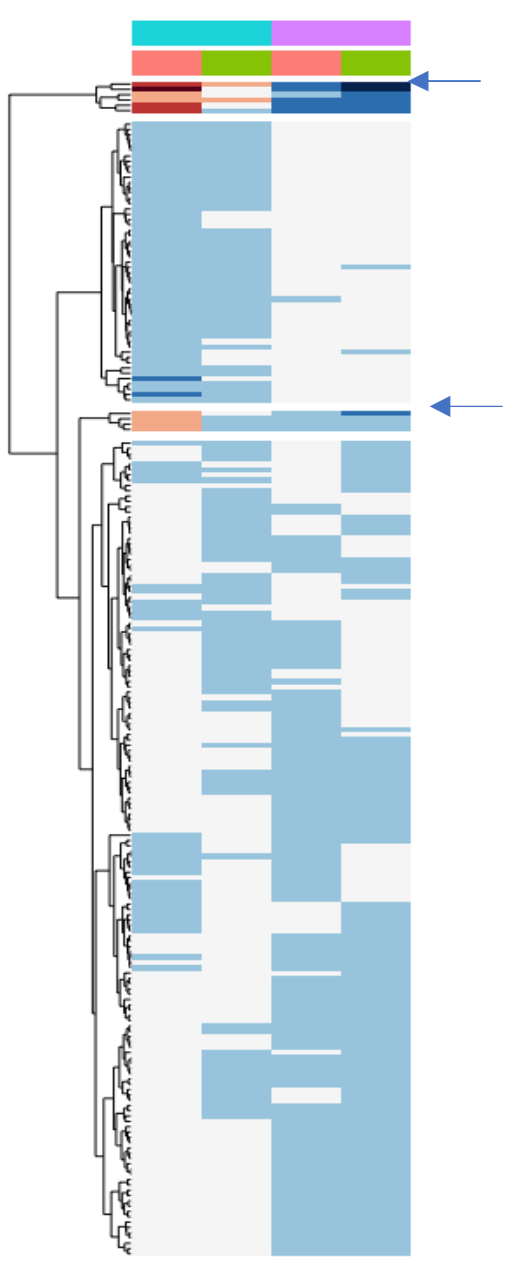

b) Cluster 1 
bioRxiv preprint doi: https://doi.org/10.1101/2020.12.15.422940; this version posted December 22, 2020. The copyright holder for this preprint (which was not certified by peer review) is the author/funder, who has granted bioRxiv a license to display the preprint in perpetuity. It is made available under aCC-BY 4.0 International license.

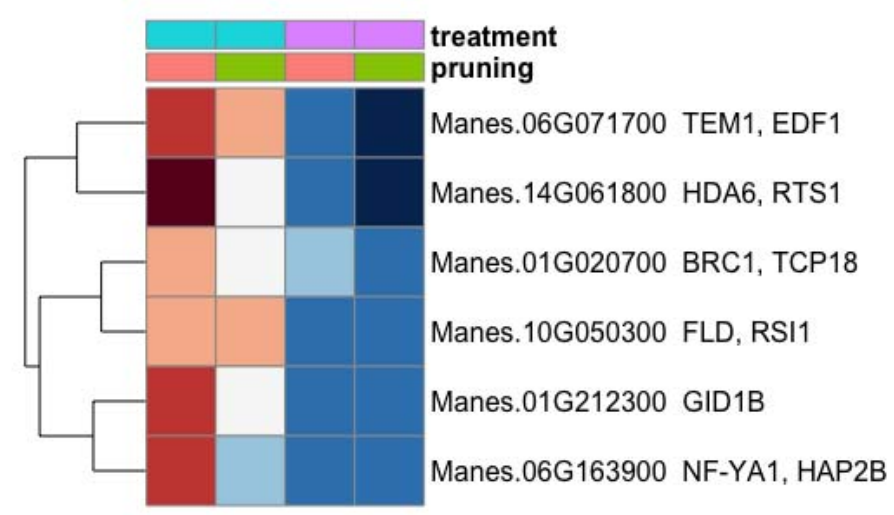

747

c) Cluster 2

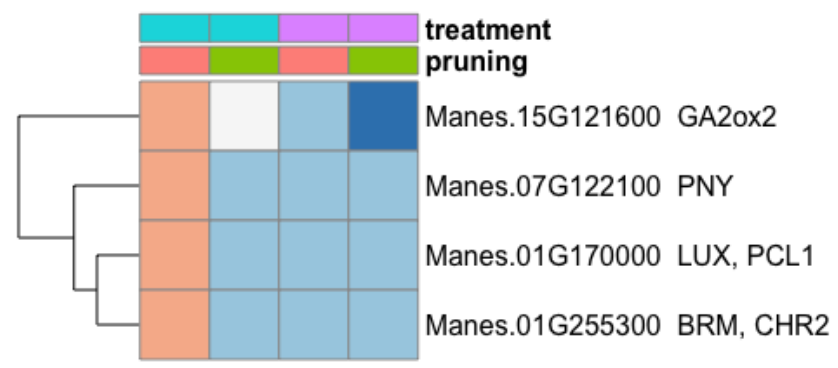

748 Figure 10 Differentially expressed flowering genes (a); details for Clusters of genes with large fold 749 changes are shown in (b) and (c). 